\title{
Polymorph nickel titanate nanofibers as bifunctional electrocatalysts towards hydrogen and oxygen evolution reactions
}

Kumar, B. Sachin ; Tarafder, Kartick; Shetty, Akshatha R.; Hegde, A. Chitharanjan; Gudla, Visweswara C.; Ambat, Rajan; Kalpathy, Sreeram K.; Anandhan, S.

\section{Published in:}

Dalton Transactions

Link to article, DOI:

10.1039/c9dt01932d

Publication date:

2019

Document Version

Peer reviewed version

Link back to DTU Orbit

Citation $(A P A)$ :

Kumar, B. S., Tarafder, K., Shetty, A. R., Hegde, A. C., Gudla, V. C., Ambat, R., Kalpathy, S. K., \& Anandhan, S. (2019). Polymorph nickel titanate nanofibers as bifunctional electrocatalysts towards hydrogen and oxygen evolution reactions. Dalton Transactions, 48, 12684-12698 . https://doi.org/10.1039/c9dt01932d

\section{General rights}

Copyright and moral rights for the publications made accessible in the public portal are retained by the authors and/or other copyright owners and it is a condition of accessing publications that users recognise and abide by the legal requirements associated with these rights.

- Users may download and print one copy of any publication from the public portal for the purpose of private study or research.

- You may not further distribute the material or use it for any profit-making activity or commercial gain

- You may freely distribute the URL identifying the publication in the public portal 


\title{
Polymorph Nickel Titanate Nanofibers as Bifunctional Electrocatalyst Towards Hydrogen and Oxygen Evolution Reactions
}

\author{
B. Sachin Kumar, ${ }^{1}$ Kartick Tarafder, ${ }^{2}$ Akshatha R. Shetty, ${ }^{3}$ A. \\ Chitharanjan Hegde, ${ }^{3}$ Visweswara C. Gudla, ${ }^{4}$ Rajan Ambat, ${ }^{4}$ Sreeram \\ K. Kalpathy, ${ }^{5}$ S. Anandhan, ${ }^{1 *}$
}

${ }^{1}$ Department of Metallurgical and Materials Engineering, National Institute of Technology Karnataka, Mangalore 575025, India.

${ }^{2}$ Department of Physics, National Institute of Technology Karnataka, Mangalore 575025, India.

${ }^{3}$ Department of Chemistry, National Institute of Technology Karnataka, Mangalore 575025, India.

${ }^{4}$ Section of Materials and Surface Technology, Department of Mechanical Engineering, Technical University of Denmark, Produktionstorvet, Dk-2800 Kgs. Lyngby, Denmark.

${ }^{5}$ Department of Metallurgical and Materials Engineering, Indian Institute of Technology Madras, Chennai 600036, India.

*Corresponding author, email id: anandtmg@gmail.com Phone number: +91-9663054756 (Mobile) $+91-824-2473762$ (Office)

Electronic Supplementary Information (ESI) available 


\begin{abstract}
\end{abstract}
Producing pure $\mathrm{H}_{2}$ and $\mathrm{O}_{2}$ to sustain the renewable energy sources with minimal environmental damage is a key objective of photo/electrochemical water-splitting research. Metallic Ni-based electrocatalysts are expensive and eco-hazardous. This has rendered the replacement or reduction of Ni content in Ni-based electrocatalysts a decisive criterion in the development of bifunctional electrocatalytic materials. In the current study, spinel/ilmenite composite nickel titanate (NTO) nanofibers were synthesised using sol-gel assisted electrospinning followed by pyrolysis at different soaking temperatures (viz., 773, 973, and $1173 \mathrm{~K}$ ). The presence of defective spinel NTO phase (SNTO) distributed uniformly along the nanofibers was confirmed by X-ray photoelectron and Raman spectroscopy. The electron micrographs revealed the morphological change of NTO nanofibers from mosaic to bamboo structure with increase in pyrolysis soaking temperature. The electrocatalytic activity of NTO nanofibers obtained at different pyrolysis soaking temperatures for alkaline water-splitting was studied. The highly defective SNTO manifests properties similar to the metallic Ni and favours $\mathrm{H}_{2}$ evolution through hydrogen evolution reaction (HER) by adsorbing more $\mathrm{H}^{+}$ions on active sites. In contrast, the ilmenite NTO favours $\mathrm{O}_{2}$ discharge. These results are explained based on the morphology of the NTO nanofibers. The mosaic structure which has higher porosity and 
greater SNTO content shows excellent HER performance. On the contrary, the large bamboo structured NTO nanofibers which has lesser porosity and SNTO content, cage the bigger $(\mathrm{OH})_{\text {ads }}$ ions at its catalytic sites to facilitate OER performance.

Keywords: Electrospinning, nickel titanate, spinel, electrocatalyst, density functional theory 


\section{INTRODUCTION}

The global demand for clean and renewable energy technologies has increased extensively during the last few decades. In this context, hydrogen is being looked upon as the energy alternative for the next century. Water electrolysis is one of the greener and cleaner ways for the large scale production of $\mathrm{H}_{2}$ gas, scoring over other industrial methods such as hydrolysis via metal hydrides or steam reforming of hydrocarbons. ${ }^{1}$ However, water electrolysis is more efficient in acidic conditions for hydrogen evolution reaction (HER) and alkaline condition for oxygen evolution reaction (OER). ${ }^{2,3}$ The downside is that these involve the use of precious noble metals as electrocatalysts, such as Pt-based material for HER and Ru- or Ir-based material for OER. ${ }^{3,4}$ The efficient, economical, and eco-friendly electrocatalyst is a vital prerequisite for water-splitting technology. Several efforts have been directed in recent times towards replacing these materials with transition metal-based materials. ${ }^{5}$ Among these, Ni-based materials have especially emerged as promising candidates for both electrocatalyst and photocatalyst applications. ${ }^{6,7}$

In the fields of electrocatalysis and photocatalysis, Ni-based materials have gained increasing attention for their bifunctional electrocatalytic activity. In other words, they can simultaneously catalyse HER and OER in the same media, which helps in obtaining improved 
water-splitting efficiency and cost-effective large scale $\mathrm{H}_{2}$ production. ${ }^{8,9}$ Besides, multiple adsorption/desorption processes that occur during electrolysis can be synchronized by using heterostructures of Ni-based materials, thereby forming more active catalytic sites. Many Nibased heterostructures have been explored in literature for their applicability as electrocatalysts $^{6}$ as well as photocatalysts ${ }^{7}$, such as $\mathrm{Ni}-\mathrm{W}$ alloy ${ }^{10}, \mathrm{Co}-\mathrm{Ni}$-graphene composite ${ }^{11}$, $\mathrm{Ni}(\mathrm{OH})_{2} / \mathrm{Ni}^{12}, \mathrm{NiTiO}_{3} / \mathrm{Ni}^{13}, \mathrm{NiO} / \mathrm{TiO}_{2}{ }^{14}$. However, these materials as electrocatalysts have some drawbacks such as high overpotential or are based on metallic Ni. Metallic Ni being expensive and easily vulnerable to environment hazards, an alternative idea is to use highly defective oxides, which inherit semi-metallic properties.

In this work, we explore the use of polymorph nickel titanate (NTO) as electrocatalyst without compromising the efficiency of HER and OER kinetics attainable by metallic Ni-based systems. Nickel titanate (NTO) heterostructures are known to exhibit superlative performance as electrocatalyst ${ }^{13-16}$, in addition to their photocatalytic performance for water-splitting applications. ${ }^{17-19}$ Herein, we report the fabrication of a composite electrode containing the polymorph NTO phases having different crystal structures, namely ilmenite (INTO, $\mathrm{NiTiO}_{3}$ ) and spinel ( $\mathrm{SNTO}, \mathrm{Ni}_{2.62} \mathrm{Ti}_{0.69} \mathrm{O}_{4}$ ). The synthesis and exclusive formation of polymorph NTO nanofibers from sol-gel assisted electrospinning followed by pyrolysis has been reported in our 
previous study. ${ }^{20}$ The band gap of the material, especially in heterostructures, determine the kinetic of photo/electrochemical reactions for which such systems are used. ${ }^{18,19,21-23}$ Hence, it is very important to understand the excitation dynamics in the band structure, that produces electron-hole pair. Some previous studies have focused on modelling the stable and distorted crystal structure of INTO using density functional theory (DFT), and its consequent effects on the electronic, structural, optical, and vibrational peculiarities of INTO. ${ }^{24-26}$ However, to our knowledge no attempts have been made to understand such features in the highly defective and non-stochiometric SNTO. In present study, we have used DFT to analyse the electronic and optical properties of SNTO, and then compare with those of INTO. Besides, using suitable structural characterization techniques and electrochemical studies, the possible mechanisms responsible for improved electrocatalytic efficiency of polymorph NTO are discussed.

\section{MATERIALS AND METHODS}

Potassium hydroxide $(\mathrm{KOH})$ pellets were purchased from Nice Chemicals, India. Poly(vinylidene fluoride) (PVDF, $\overline{M_{v}}=575 \mathrm{~kg} \cdot \mathrm{mol}^{-1}$ ) was procured from Prakash Chemical Private Limited, India. N, N- dimethylformamide (DMF) was bought from Sisco Research Laboratories Private Limited, India. Commercial Platinum on graphitized carbon $(\mathrm{Pt} / \mathrm{C}$, 
20 wt.\% Pt loading on Vulcan XC 72 of Pt particle size $<5 \mathrm{~nm}$ ) and commercial Ruthenium (IV) oxide $\left(\mathrm{RuO}_{2}\right.$, assay 99.9\%) powders were procured from Sigma-Aldrich, India. No additional purification was done for these chemicals (assay $>99 \%$ ). Graphite rods to prepare working electrodes (WE) were procured from Speciality Graphites, India. The synthesis of NTO nanofibers are explained in detail elsewhere. ${ }^{20}$ In brief, the precursor nanofibers are developed from sol-gel assisted electrospinning for optimal process parameters. Later, these electrospun precursor nanofibers were pyrolyzed on a quartz plate in Muffle furnace at three different pyrolysis temperatures, $T$ (viz. 773,973 , and $1173 \mathrm{~K}$ ) for $2 \mathrm{~h}$ an then annealed to obtain NTO nanofibers.

A field emission scanning electron microscope (FESEM, ULTRA 55, Gemini, Carl Zeiss, Germany) was used to obtain the micrographs of the NTO nanofibers. The average diameter of the fibre (AFD) and its standard deviation (SD) were estimated from FESEM micrographs. The approximate elemental composition at the selected area on the nanofibers was obtained using energy dispersive spectrometer (EDS, X-Max, Oxford instruments, UK). To record and analyse the morphology of nanoparticles, high-resolution images of lattice fringes of polycrystalline NTO nanofibers were obtained by selected area diffraction (SAED) 
on a transmission electron microscope (HRTEM, JEM 2100, JEOL, USA), operating at accelerating voltage of $200 \mathrm{keV}$.

The diffuse reflectance absorption spectra were acquired using UV-vis-NIR spectrometer $\left(3600+\right.$, Hitachi, Japan) in the wavenumber range of 5000 to $50,000 \mathrm{~cm}^{-1}$. To determine the Raman shift of NTO nanofibers obtained at different pyrolysis soaking temperature, Raman spectrometer (LabRAM HR, Horiba, Japan) was used. The Raman spectrometer used was equipped with laser source of power $28 \mathrm{~mW}$ and a wavelength of $532 \mathrm{~nm}$. The Raman spectra were acquired in the wavenumber range of 50 to $1600 \mathrm{~cm}^{-1}$. The photoluminescence (PL) emissions spectra of NTO nanofibers were recorded using PL spectrometer (Fluoromax-4 Spectrofluorometer, Horiba, France) excited with $325 \mathrm{~nm}$ photon in the wavenumber range of 16,000 to $29,000 \mathrm{~cm}^{-1}$.

In order to understand the intermediate band-gap and optical characteristics of INTO and SNTO, first-principles density functional theory (DFT) calculations were carried out using projector augmented wave method implemented in Vienna ab-initio simulation package (VASP). Generalized gradient approximation (GGA) under Perdew-Burke-Ernzerhof parametrization $(\mathrm{PBE})$ was used for treating the exchange-correlation potential. However, this alone does not remove the ambiguity of electron self-interaction term in DFT. Hence, to 
prevent unwanted delocalized d- and f-electrons, onsite Coulomb interaction correction was introduced using GGA $+\mathrm{U}$ method. ${ }^{24,27}$ A grid of $7 \times 7 \times 7$ Monkhorst Pack k-points was used for reciprocal space sampling. The wave functions were expanded in the plane wave basis with a sufficiently large kinetic energy cut-off of $500 \mathrm{eV}$. Hellmann-Feynman theorem was used to calculate the forces on each atom. Subsequently, these were used to perform a conjugate gradient structural relaxation until the forces on the atoms reduced to less than $1 \mathrm{meV} \cdot \AA^{-1}$. The electronic band structure and density of sates (DOS) of INTO and SNTO were investigated when their respective unit cells were having optimized structure with minimum total energy. Finally, the optical conductivity was calculated within a range of $0-50 \mathrm{eV}$ using random phase approximation.

To determine the valence states of the elements, present in NTO nanofibers, X-ray photoelectron spectrometer (XPS, K-Alpha, Thermo Scientific, USA) was used. A monochromatic $\mathrm{Al} \mathrm{K}_{\alpha}$ radiation $(1486.6 \mathrm{eV})$ was employed to obtain survey spectra in the range 0 to $1350 \mathrm{eV}$ with pass energy of $200 \mathrm{eV}$ for NCO nanofibers. To record the highresolution spectra for $\mathrm{Ni} 2 p$, Ti $2 p$, and $\mathrm{O} 1 s$, a pass energy of $50 \mathrm{eV}$ was used. For each sample, 10 scans were performed, the $\mathrm{C} 1 \mathrm{~s}$ line at $285.0 \mathrm{eV}$ was used as a reference to measure the binding energies of elements at a precision of $\pm 0.1 \mathrm{eV}$. The samples were examined at a spot 
size $\varnothing 400 \mu \mathrm{m}$ and the photoelectrons were collected at $90^{\circ}$ with respect to the sample surface.

The operating base pressure was around $2 \times 10^{-8}$ mbar in the XPS chamber. The depth profiling was carried out to understand the distribution of different ions within NTO nanofibers obtained at pyrolysis soaking temperature of $773 \mathrm{~K}$. During depth profiling, the $\mathrm{Ar}^{+}$ion bean was sputtered for $25 \mathrm{~s}$ to sputter away the sample and attain a new surface at each depth. The deconvolution of the high-resolution XPS spectra of all the elements for each sample was done using Origin software (2016, OriginLab, USA).

The graphite electrodes were modified to fabricate WE (i.e. GE) as follows: one end of the rod was glassy polished, whereas, the other end was soldered with insulated wire circuit connections. The electrode was sealed on the side walls as well as circuit connection ends using Teflon tape to have no current or electrolyte leak. The polished end was sonicated in ethanol for an hour and then dried. The electrocatalyst ink having a concentration of $10 \mathrm{mg} \cdot \mathrm{mL}^{-1} \mathrm{NTO}$ nanofibers and $0.1 \mathrm{mg} \cdot \mathrm{mL}^{-1}$ of carbon black (to improve adhesiveness) was prepared by dispersing them in ethanol by ultrasonication for an hour. Similarly, the control GE was prepared without NTO nanofibers. Later, $1 \mathrm{~mL}$ of this electrocatalyst ink was pipetted on the polished surface of the GE and dried in air. After the coated surface is completely dried, $10 \mu \mathrm{L}$ of $0.5 \%$ PVDF solution on DMF was loaded to keep the NTO nanofiber/carbon black deposit 
in position. The GEs were prepared from NTO nanofibers obtained at pyrolysis soaking temperatures, $773 \mathrm{~K}, 973 \mathrm{~K}$, and $1173 \mathrm{~K}$.

The electrochemical measurements were performed on an electrochemical workstation (VersaSTAT 3, Ametek Scientific Instruments, USA) with a three-electrode cell set up as shown in Figure 1. The cell comprises GE coated with electrocatalyst as WE (effective surface area $=100 \mathrm{~mm}^{2}$, a platinum foil of same surface area as counter electrode $(\mathrm{C})$, and a saturated calomel electrode (SCE) as a reference electrode (R). The SCE was connected through the Luggin's capillary with Agar- $\mathrm{KCl}$ salt bridge, to eliminate the error due to Ohmic drop. The GE were submerged for an hour in the electrolyte $\left(\mathrm{N}_{2}\right.$ saturated $\left.1 \mathrm{M} \mathrm{KOH}\right)$ before electrochemical studies, to attain equilibrium. The alkaline water electrolysis efficiency of NTO nanofibers obtained at different pyrolysis temperature were analysed using cyclic voltammetry $(\mathrm{CV})$ and chronopotentiometry $(\mathrm{CP})$ techniques and monitoring the HER and OER kinetics. It must be noted that NTO has natural photocatalytic properties due to its wide range of band-gaps in visible light region. Hence, all the electrochemical measurements were made in the same timeline of 3:00 to 5:00 PM as per Indian standard time, in a closed room environment under a fluorescent lamp. 


\section{RESULTS AND DICUSSION}

\subsection{Structural and Stoichiometry characterisation}

The FESEM-EDS images (Figure S2, ESI) unveils the morphology, structure and selected area stoichiometry of the NTO nanofibers. The mosaic structured NTO nanofibers possesses higher surface area and porosity at lower pyrolysis temperature (at $\mathrm{T}=773 \mathrm{~K}$, surface area $=166.7$ $\mathrm{m}^{2} \cdot \mathrm{g}^{-1}$, Ref. [20]) that promotes the diffusion of electrolytes, whereas the bamboo structured NTO nanofibers obtained at $1173 \mathrm{~K}$ (surface area $=22.91 \mathrm{~m}^{2} \cdot \mathrm{g}^{-1}$, Ref. [20]) enable fast charge transfer during electrocatalysis. The molar ratio of $\mathrm{Ni} / \mathrm{Ti}(\sim 2.2)$ from EDS spectra suggests the non-stoichiometric phase present in the system. The mechanism for formation of this defective phase (i.e. SNTO) has been discussed in detail elsewhere. ${ }^{20}$ It must be noted that apart from point defects, dislocations in the crystallite act as active sites for electrochemical reactions. The crystallite sizes $(D)$ of both INTO and STNO present in the nanofibers were calculated by the XRD pattern via Williamson-Hall plot. ${ }^{20}$ The crystallite size thus estimated was used to calculate the dislocation density $(\delta)$ in NTO nanofibers by following equation: ${ }^{28,29}$

$$
\delta=\frac{n}{D^{2}}
$$


where $n$ is a factor ( $n=1$ for minimum dislocation density). The dislocation densities for INTO and SNTO of nanofibers obtained for different pyrolysis temperature are tabulated in

Table 1. The $\delta$ decreases with increase in pyrolysis soaking temperature. This influences the electrochemical reactions, because the charge transfer resistance decreases with increase in $\delta$ .${ }^{30}$ This suggests that samples obtained at $773 \mathrm{~K}$ are more active for electrolysis. TEM images of NTO nanofibers obtained at different pyrolysis temperature are shown in Figure 2. The NTO grains obtained from pyrolysis at $773 \mathrm{~K}$ (Figure 2a) are loosely packed in contrast to the dense grains obtained at higher pyrolysis temperature ( $973 \mathrm{~K}$ and $1173 \mathrm{~K}$, Figure 2b, c). Figure 2 also reveals the polycrystalline nature of the NTO grains as seen from SAED patterns with lattice fringes indexed correspondingly to INTO and SNTO. At close inspection it can be observed that the NTO grains transform their shapes from irregular ellipsoidal to regular polygon with increase in pyrolysis temperature.

Figure 3a shows the UV-vis-NIR diffuse reflectance spectra of NTO nanofibers obtained at different pyrolysis temperature. Besides the surface carbon moieties from precursor, the absorbance peaks at lower wavenumber are attributed to $\mathrm{Ni}^{2+} d-d$ transitions, i.e. ${ }^{3} A_{2 g}(F) \rightarrow{ }^{3} T_{2 g}(F)$ and ${ }^{3} A_{2 g}(F) \rightarrow{ }^{3} T_{1 g}(F)$, respectively. Furthermore, two peaks apparent for nanofibers obtained at higher pyrolysis temperatures (973 K and $1173 \mathrm{~K}$ ) are ascribed to 
the crystal field splitting of $3 d^{8}$ band of $\mathrm{Ni}^{2+}$ ions, that split up into two sub-bands called the $N i^{2+} \rightarrow T i^{4+}$ charge-transfer (CT) bands..$^{20}$ The absence of these sub-band peaks for $773 \mathrm{~K}$ NTO sample suggests the high structural disorder in the material, which could either be nonstoichiometry defects or dislocations in the material with small crystallite/grain size. The broad absorption edge at higher wavenumber is ascribed to $O^{2-} \rightarrow T i^{4+} \mathrm{CT}$ band. ${ }^{17,20}$

The Raman spectra of NTO nanofibers obtained at different pyrolysis temperature are shown in Figure $3 \mathrm{~b}$. For INTO structure with $C_{3 i}^{2}$ symmetry and $R \overline{3}$ space group, all the ten Raman active modes $\left(5 A_{g}+5 E_{g}\right)$ are observed in the range of $150-800 \mathrm{~cm}^{-1} \cdot{ }^{17,31}$ These peaks are characteristic peaks of INTO and the same are assigned for NTO nanofibers in present study, especially NTO nanofibers obtained at higher pyrolysis temperature. The well-defined peaks at higher pyrolysis temperature are due to the structural order, as the intensity of the peak is function of scattering efficiency of the material. Hence, the ambiguous peaks were noticed for NTO nanofibers obtained at $773 \mathrm{~K}$ having high structural disorder. However, the peak around $773 \mathrm{~cm}^{-1}$ remain unassigned even with both experimental ${ }^{31}$ and theoretical (nanocrystallite) $)^{23}$ studies until the present study. Here, from our previous study on $\mathrm{SNTO}^{20}$ and by comparing the Raman spectra of spinel structures ${ }^{32}$, we suggest that this peak belongs 
to Raman mode of $A_{1 g}$ for SNTO. Furthermore, this also corroborates the presence and existence of SNTO phase in nanofibers.

The PL emission peak (Figure 3c) around $2.2 \mathrm{eV}(562 \mathrm{~nm})$ is attributed to the colour of the material. Furthermore, the emission peaks between 2.5-2.8 eV correspond to electron-hole transitions originated by defects levels in the band gap, such as oxygen and titanium vacancies, surface moieties. ${ }^{33}$ These defects decrease as function of increase in pyrolysis temperature as more oxygen is incorporated into the system. The apparent peak $\sim 3 \mathrm{eV}$ is ascribed to $\mathrm{Ti}^{4+} \rightarrow \mathrm{O}^{2-}$ intrinsic CT which is prominent in well-defined structure, as structurally disordered NTO nanofibers (obtained at $773 \mathrm{~K}$ ) have less chance of such CT interactions. The CIE 1931 plot obtained for the PL spectra in Figure 3d. The CIE plot shows a noteworthy shift of NTO nanofibers with increase in pyrolysis temperature, which demonstrate amalgamation of additional oxygen to the system.

The structural and physical properties of various ilmenite type titanates are studied theoretically using DFT analysis. ${ }^{24,34}$ To have the additional insight of the NTO phases (INTO and SNTO) over the competing band gaps for electrocatalyst or photocatalyst phenomena, the conduction band (CB) and valence band (VB) were estimated by first principles DFT 
calculations. Figure $4 \mathrm{a}$ and $4 \mathrm{~b}$ shows the DOS of INTO and SNTO, respectively. Apart from multiple band gaps mentioned in previous study ranging from $2.4-2.7 \mathrm{eV},{ }^{20}$ two new band gaps were observed from our electronic structure calculations, i.e. $1.07 \mathrm{eV}$ and $1.56 \mathrm{eV}$ for INTO. And, $0.3 \mathrm{eV}$ and $0.81 \mathrm{eV}$ intermediate narrow band gaps were obtained for SNTO. The former $1.56 \mathrm{eV}$ into INTO can be attributed to the absorbance peak for the ${ }^{3} A_{2 g}(F) \rightarrow{ }^{3} T_{2 g}(F)$ due to $\mathrm{Ni}^{2+} d-d$ transitions (as seen from Figure 3a). The latter, $1.07 \mathrm{eV}$ of INTO and $0.81 \mathrm{eV}$ of SNTO to ${ }^{3} A_{2 g}(F) \rightarrow{ }^{3} T_{1 g}(F)$ and its shoulder peak, which confirms the theoretical band gap is close to the value obtained from that of the experiments. The pseudo band gaps around $0.3 \mathrm{eV}$ or sometimes less than $\sim 1.5 \mathrm{eV}$ are due to hybridisation of strong covalent character Ni-O bonds, which is believed to hinder the $N i^{2+} \rightarrow T i^{4+} \mathrm{CT} .{ }^{18,35}$ These transitions are in visible and infrared light region and hence suggests its photocatalytic behaviour. For both INTO and SNTO phases, the VB is primarily fabricated of $\mathrm{Ni} 3 d$, and $\mathrm{CB}$ of $\mathrm{Ti} 3 d$, whereas there are additional subbands for both the phases above VB minima and below CB maxima. This result of INTO is in contrary to the DOS obtained in literature, where VB is predominant by $\mathrm{O} 2 p$ orbitals $\mathrm{s}^{25}$, whereas comparable to the other literature..$^{23,35,36}$ 
The band structure of INTO and SNTO in Figure S3a and 3b, conveys that the SNTO is semi-metallic nature with closet to Fermi level being completely occupied. However, unoccupied states are seen in VB or high CB. This can be attributed to highly defective phase of SNTO having oxygen vacancies or possibility of existence of intermetallic connection (NiO-Ti-O-Ni) as previously reported. ${ }^{24}$ However, such states have been confirmed with $\mathrm{NiCo}_{2} \mathrm{O}_{4}$ and $\mathrm{NiO} / \mathrm{TiO}_{2}$ DFT study, where favours in electrochemical redox reaction as communicative media for charge transfer and water absorption. ${ }^{14,37}$ If such semi-metallic/metallic states exists with the INTO, it has also been proven to increase the efficiency of catalyst for electrochemical water-splitting $\left(\mathrm{NiTiO}_{3} / \mathrm{Ni}\right)$, experimentally. ${ }^{13}$

The optical conductivity of the INTO and SNTO were estimated from DFT analysis are shown in Figure 5 ranging 0 to $50 \mathrm{eV}$. The peaks below $50 \mathrm{eV}$ belong to the UV-vis light assisted inter-band transitions in the material. The hyperchromic effect for both INTO and SNTO are observed in the range of $4-7 \mathrm{eV}$ due to the CT interactions in respective material. The optical conductivity reaches maxima at $4.46 \mathrm{eV}$ and $5.96 \mathrm{eV}$ for SNTO and ITNO, respectively. This suggests they are promising photocatalyst and electrocatalyst. A second maxima peak is observed for INTO around $19.21 \mathrm{eV}$, which decreases and shifts to lower energy $(13.15 \mathrm{eV})$ in case of SNTO. This indicates that INTO is more optically conductive to 
the incident photons of higher energies. The bathochromic shift in SNTO can be attributed to the smaller band gaps or rich $\mathrm{Ni}$ ion concentration. ${ }^{38,39}$ The overall picture of variation in the peaks of optical conductivity concludes the change in the band gaps of INTO and SNTO, expressing different behaviour for incident photons.

XPS studies were performed to confirm the elemental composition and valence states of elements present for three different samples pyrolyzed at temperature 773,973 , and $1173 \mathrm{~K}$ Figure S4. The XPS depth profiling was carried out to understand the anatomy of NTO nanofibers obtained at $773 \mathrm{~K}$ (Figure 6), which seem to possess high structural disorder compared to the other two samples. Figure S4a shows wide scan XPS spectra of samples pyrolyzed at different temperature, and Figure 6a shows the XPS survey spectra of NTO nanofibers obtained at surface and two different depths of $773 \mathrm{~K}$ NTO nanofibers. Both the survey spectra Figure S4a and 6a confirms the presence of C, O, Ti, and Ni elements ${ }^{13,40,41}$ distributed non-homogeneously over the NTO nanofibers (ratio of intensity of respective elements is not equal to one). ${ }^{11}$ The deconvoluted high-resolution spectra of $\mathrm{Ni} 2 p$, Ti $2 p$, and O Is (Figure S4b-d) confirms the formation of ilmenite NTO, which is in good accordance with literature. ${ }^{13,40,42}$ It has to be noted that the deconvoluted peaks in each individual graph (Figure 6 and S4) are representative and similar deconvoluted peaks exists in all the three high- 
resolution spectra of corresponding graph. The presence of defective $\mathrm{O}^{2-}$ (Figure $\mathrm{S} 4 \mathrm{~b}$ ) even in XPS depth profiling (Figure 6b) suggests that these are not oxygen moieties or absorbed surface oxygen compounds, whereas distributed over bulk sample. This observation indeed helps in predicting the presence of SNTO in the NTO nanofibers.

The high-resolution Ni $2 p$ spectra observed in all samples as shown in Figure S4c and $6 c$, suggests the presence of typical octahedral $\mathrm{Ni}^{2+}$ ions (characteristic $2 p$ spin orbital splitting separated by $\sim 17.3 \mathrm{eV}$ ) in both INTO and SNTO. ${ }^{40,41}$ It has to be noted that the $\mathrm{Ni}^{2+}$ ions in both crystal structures remain in octahedral void. ${ }^{20}$ The hypsochromic shift in Ni $2 p$ spectra of $\mathrm{Ni}^{2+}$ ions present in SNTO is attributed to the subtle change in ion charge by oxidation, i.e. $\mathrm{Ni}^{2+\delta}$, which promote stability of non-stoichiometry SNTO having oxygen deficiency. ${ }^{43}$ Furthermore, Figure $6 \mathrm{c}$ shows the existence of $\mathrm{Ni}^{0}\left(2 p_{3 / 2} \mathrm{ca} .852 .3 \mathrm{eV} \text { and } 2 p_{1 / 2} \mathrm{ca} .869 .4 \mathrm{eV}\right)^{13}$ after $\mathrm{Ar}^{+}$ion sputtering during XPS depth profiling. This is ascribed to metallic Ni which are formed due to the reduction of high valence Ni ions during $\mathrm{Ar}^{+}$ion bombardment. ${ }^{44}$ It is well known that the $\mathrm{Ti}^{4+}$ ions occupy only the octahedral voids in INTO, and tetrahedral voids in SNTO. ${ }^{20}$ The octahedrally and tetrahedrally located $\mathrm{Ti}^{4+}$ ions are easily distinguished in the high-resolution XP spectra of $\mathrm{Ti} 2 p$ (Figure $\mathrm{S} 4 \mathrm{~d}$ and $6 \mathrm{~d}$ ), which is consistent with the literature. ${ }^{45,46}$ However, the presence of $\mathrm{Ti}^{4-\delta}$ may be due to (i) charge neutrality in non- 
stoichiometry SNTO, (ii) the reduction to low valent ion during XPS depth profiling, which is negligible due to low concentration of Ti ions in SNTO $\left(\mathrm{Ni}_{2.62} \mathrm{Ti}_{0.69} \mathrm{O}_{4}, \mathrm{Ni} / \mathrm{Ti} \sim 3.8\right)^{20,47}$, or (iii) partial reduction of $\mathrm{Ti}^{4+}$ ions during $\mathrm{Ar}^{+}$ion etching. ${ }^{44}$ Besides, the peak representing $2 p_{1 / 2} \mathrm{Ti}^{4-}$ ${ }^{\delta}$ ion due to oxygen deficiency ${ }^{48}$, might have been convoluted with tetrahedral $2 p_{3 / 2} \mathrm{Ti}^{4+}$ ions. It must be noted that $2 p_{1 / 2} \mathrm{Ti}^{4-\delta}$ ion have lower orbital energy than $2 p_{3 / 2} \mathrm{Ti}^{4-\delta}$ (inset Figure $\mathrm{S} 4 \mathrm{~d}$ and $6 \mathrm{~d}$ ) and hence the partial reduction in ionic charge is fulfilled by addition of electrons to lower valence. This clarifies the absence of $2 p_{3 / 2} \mathrm{Ti}^{4-\delta}$ peak in Ti $2 p$ XP spectra of the samples. These results further corroborate the presence of SNTO in NTO nanofibers.

\subsection{Bifunctional electrocatalyst for water-splitting}

\subsubsection{Hydrogen evolution reaction (HER)}

The electrocatalytic HER of NTO/GE nanofibers in alkaline medium was studied via CV and CP methods, and electrocatalytic parameters were evaluated by Tafel plots. In electrochemistry, HER is comprehensively studied through its ease in producing pure hydrogen gas. The protons from the electrolyte are adsorbed on the active sites of the electrocatalyst surface (cathode) through HER and receive electrons to form chemisorbed hydrogen atoms, which later disengage as hydrogen gas. ${ }^{11,49,50}$ In this regard, CV analysis is a well-established technique to comprehend the thermodynamics of redox reactions and kinetics of adsorption 
process. Besides, the $\mathrm{CP}$ analysis is a basis for evaluating the material stability, where a definite controlled current is applied between electrodes (three electrode system) as the redox reactions occur at the active sites of the working electrode.

Figure 7 shows the results of the CV analysis for HER. For all working electrodes during HER, CV analysis was conducted in a negative potential range (0 to $-1.6 \mathrm{~V})$ with 50 cycles under $1 \mathrm{M} \mathrm{KOH}$. The optimal scan rate for the HER efficiency of NTO/GE was selected based on the CV tests of NTO nanofibers obtained at $773 \mathrm{~K}$ at different scan rates $(5,25,50$, and $\left.100 \mathrm{mV} \cdot \mathrm{s}^{-1}\right) .{ }^{49}$ The maximum peak current attained after equilibrium was observed for the scan rate of $100 \mathrm{mV} \cdot \mathrm{s}^{-1}$ for the stable cycle. Hence, $\mathrm{CV}$ analysis for all working electrodes were performed at this scan rate. Furthermore, the peak current at $-1.6 \mathrm{~V}$ decreased sequentially for each sample during 50 cycles of $\mathrm{CV}$ analysis until it attained an equilibrium and became constant for the rearmost cycles. This retarding peak current within 50 cycles is attributed to the increase in resistance instituted by the hydrogen bubbles formed on the NTO/GE surface. Later, these hydrogen bubbles stabilize once they attain equilibrium in the formation and detachment of hydrogen gas which leads to constant peak current for hindmost cycles. From Figure 7 and Table 1, it is found that the least cathodic onset potential $(-0.69 \mathrm{~V})$ and highest cathodic current were observed for NTO/GE obtained at $773 \mathrm{~K}$. This highest electrocatalytic 
activity of NTO nanofibers pyrolyzed at $773 \mathrm{~K}$ is attributed to the high surface area, morphology and defective active sites (especially from non-stoichiometric SNTO) which will be further discussed in Section 3.2.3. The onset potential of state-of-the-art of commercial $\mathrm{Pt} / \mathrm{C} / \mathrm{GE}(-0.935 \mathrm{~V})$ was compared with the NTO/GE obtained at different $\mathrm{T}$ in Table 2, it was found that NTO/GE electrodes had minimum onset potential than that of $\mathrm{Pt} / \mathrm{C} / \mathrm{GE}$ electrode, suggesting its better performance.

The typical operating current densities for the conventional low-pressure alkaline electrolysers in industry range from -100 to $-300 \mathrm{~mA} \cdot \mathrm{cm}^{-2} .{ }^{11}$ To evaluate the electrocatalytic behaviour of the electrodes, $\mathrm{CP}$ analysis was monitored at a constant current density applied over sufficient period. The $\mathrm{CP}$ analysis for the liberation of hydrogen on NTO/GE electrodes were obtained at a constant current of $-300 \mathrm{~mA}$ for a period of $1800 \mathrm{~s}$. This optimal stable current for hydrogen gas evolution was fixed after measuring the amount of hydrogen gas evolved using NTO/GE obtained at $773 \mathrm{~K}$ at different applied currents (Figure S5, ESI). Furthermore, by measuring the amount of hydrogen gas evolved for the initial $300 \mathrm{~s}$, the electrocatalytic activity of all the NTO/GE electrodes obtained at different pyrolysis temperatures was estimated. The nature of $\mathrm{CP}$ plots is shown in Figure 8 for all the working electrodes and the inset Figure 8 shows the volume of hydrogen gas evolved on the corresponding working electrode for the 
initial $300 \mathrm{~s}$. The production of hydrogen gas is maximum for the NTO/GE obtained at $773 \mathrm{~K}$.

This result is an evidence for the best electrocatalytic activity of NTO/GE obtained at $773 \mathrm{~K}$

for HER in present study.

\subsubsection{Oxygen evolution reaction (OER)}

Similar to HER, the NTO/GE developed at different pyrolysis temperatures were evaluated for their electrocatalytic behaviour in OER. For OER, the CV analysis were conducted in the positive potential window of 0 to $0.75 \mathrm{~V}$ at scan rate of $100 \mathrm{mV} \cdot \mathrm{s}^{-1}$. The onset potential for incessant liberation of oxygen gas was recorded from the CV plots. From Figure 9 and Table 1, it was determined that the NTO/GE obtained at $1173 \mathrm{~K}$ showed the supreme electrocatalytic behaviour with the least anodic onset potential of $0.296 \mathrm{~V}$ towards OER, beyond which, a steep increase in the anodic current was observed. The onset potentials obtained for different NTO/GE electrodes was compared with the state-of-the-art of commercial $\mathrm{RuO}_{2} / \mathrm{GE}(0.417 \mathrm{~V})$

in Table 2, and it was found that NTO/GE electrodes had lesser onset potential and comparable.

The stability and competence of NTO/GE for OER was also studied using CP analysis. The optimal operating current density for OER was chosen on similar grounds as HER (Figure S6, ESI), but with a positive current value, i.e. $+300 \mathrm{~mA}$ for a time interval of $1800 \mathrm{~s}$. When this current was applied, the potential was found to decrease drastically as shown in CP plots 
(Figure 10), until it reached an equilibrium potential, where $\mathrm{OH}^{-}$oxidizes to $\mathrm{O}_{2}$. At this equilibrium, the oxygen gas bubbles forming at the active site of the NTO nanofiber surface and ones that are escaping attain steadiness, which keeps the potential stable throughout the experiment.

The relative volume of oxygen gas evolved in $300 \mathrm{~s}$ for NTO/GE, corresponding to different pyrolysis temperature is shown in the inset Figure 10. The NTO/GE obtained at 1173 K exhibited the least onset potential for oxygen gas liberation, in contrast to that observed for hydrogen gas liberation. This observation shows that the NTO/GE obtained at $1173 \mathrm{~K}$ was a more efficient electrocatalyst for OER. In other words, NTO/GE obtained at $1173 \mathrm{~K}$ possesses the highest electrocatalytic efficiency, presumably due to adsorption of more $\mathrm{OH}^{-}$ions on active sites of the surface from electrolyte. This can be understood by the large crystallite size of NTO nanofibers obtained at $1173 \mathrm{~K}$, which favours the colonization of the large $\mathrm{OH}^{-}$ions on the active sites though it is not the recommended material for HER (due to low surface area and lesser defective active sites), as discussed previously. On the other hand, the NTO/GE obtained at $773 \mathrm{~K}$ displays the minimum electrocatalytic competence for OER due to lack of surface activity towards $\mathrm{OH}^{-}$ions adsorption. Therefore, it could be concluded that the 
electrocatalyst surface favouring the anodic reaction has a hostile outcome on the cathodic reaction and vice versa.

\subsubsection{Tafel polarisation plot}

The electrocatalysts prepared under different pyrolysis temperature are analysed for their kinetic behaviour using Tafel polarisation plot. The Tafel plot of NTO/GE electrodes were obtained by linear sweep voltammetry at a scan rate of $5 \mathrm{mV} \cdot \mathrm{s}^{-1}$. The Tafel slopes $(\beta)$ for both the HER and OER were determined from Tafel plot (Figure 11) and tabulated in Table 1. In alkaline medium, HER in general trails through two different mechanisms either as VolmerTafel (Equation 2 and 3) or Volmer-Heyrovsky (Equation 2 and 4) process. ${ }^{11}$

The Volmer reaction by electrochemical hydrogen atom adsorption is written as:

$$
\mathrm{H}_{2} \mathrm{O}+\mathrm{M}+e^{-} \leftrightarrow \mathrm{M}-\mathrm{H}_{a d s}+\mathrm{OH}^{-}
$$

and the Tafel reaction by chemical desorption as:

$$
2 M-H_{a d s} \leftrightarrow 2 M+H_{2} \uparrow
$$

The Heyrovsky reaction by electrochemical desorption is:

$$
\mathrm{M}-\mathrm{H}_{\text {ads }}+\mathrm{H}_{2} \mathrm{O}+e^{-} \leftrightarrow \mathrm{M}+\mathrm{OH}^{-}+\mathrm{H}_{2} \uparrow .
$$


Both Volmer-Tafel and Volmer-Heyrovsky processes involve the $\mathrm{H}_{2} \mathrm{O}$ molecule adsorption, and its electrochemical reduction to adsorbed $\mathrm{H}$ atom $\left(\mathrm{H}_{\mathrm{ads}}\right)$ and $\mathrm{OH}^{-}$ion. Later, the $\mathrm{OH}^{-}$ion is desorbed to electrolyte to create fresh surface and active $\mathrm{H}_{\text {ads }}$ intermediate in formed to liberate $\mathrm{H}_{2} \cdot{ }^{11}$ Generally, depending upon the HER Tafel slope $\left(\beta_{c}\right)$, the rate-determining step is Volmer $\left(\beta_{c}>100 \mathrm{mV} \cdot \mathrm{dec}^{-1}\right)$, Heyrovsky $\left(\beta_{c}\right.$ about $\left.40 \mathrm{mV} \cdot \mathrm{dec}^{-1}\right)$, or Tafel $\left(\beta_{c}\right.$ about $\left.30 \mathrm{mV} \cdot \mathrm{dec}^{-1}\right){ }^{51}$ In case of electrochemically activated WE, the Volmer-Heyrovsky mechanism is facile and the rate-determining step is a mixed process. ${ }^{52}$ The $\beta_{c}$ for NTO/GE obtained at $773 \mathrm{~K}(58.9$ $\left.\mathrm{mV} \cdot \mathrm{dec}^{-1}\right)$ is close to Volmer-Heyrovsky mechanism and best suitable for HER compared to NTO/GE obtained at $973 \mathrm{~K}\left(77.3 \mathrm{mV} \cdot \mathrm{dec}^{-1}\right)$ and $1173 \mathrm{~K}\left(84.7 \mathrm{mV} \cdot \mathrm{dec}^{-1}\right)$. The $\beta_{c}$ for NTO/GE obtained at $773 \mathrm{~K}$ was two times lower than that of the state-of-the-art commercial Pt/C/GE (117.4 $\left.\mathrm{mV} \cdot \mathrm{dec}^{-1}\right)$, which suggests $\mathrm{NTO} / \mathrm{GE}$ electrodes outperform the $\mathrm{Pt} / \mathrm{C} / \mathrm{GE}$. It was observed that the Ni-based materials hold suitable binding energy for $\mathrm{H}_{\mathrm{ads}}$ close to $\mathrm{Pt}$, though the electrocatalytic activity for HER is less compared with $\mathrm{Pt} / \mathrm{C} .{ }^{13}$ Table 2 shows that the performance of HER activity $\left(\beta_{c}\right)$ of the NTO/GE nanofibers is better than values reported earlier in literature, which falls near to $\mathrm{Pt} / \mathrm{C}$, especially for NTO/GE obtained at $773 \mathrm{~K}$. This is attributed to the (i) uniform compositions of INTO and SNTO as seen from XPS, and (ii) 
synergetic kinetics of INTO/SNTO, where the defective SNTO behaves like a pure metallic Ni as seen from DFT analysis.

It has been reported that pure $\mathrm{Ni}$ has favourable active site for $\mathrm{H}_{\mathrm{ads}}$, whereas INTO favours the absorption of $\mathrm{OH}^{-}$ions, which also occupy the active sites of $\mathrm{H}_{\text {ads }}$ in INTO. ${ }^{11,13}$ This suggests that the $\mathrm{H}^{+}$ions towards has a rational affinity towards defective SNTO (Ni rich phase) and the large number of $\mathrm{OH}^{-}$ions adsorb at INTO active sites. Furthermore, the NTO nanofibers obtained at pyrolysis temperature of $773 \mathrm{~K}$ has greater porosity (HRTEM, Figure 2) compared to those obtained at $1173 \mathrm{~K}$. This suggests that ease of adsorption of large $\mathrm{OH}^{-}$ ions onto the active surface and follow OER process. Hence, the synergetic effect of both structural factor and compositional distribution contributes to the respective HER and OER process. It has also been reported that the presence of $\mathrm{Ti}^{4+}$ ions in INTO is advantageous to improve the stability of the electrocatalyst in case of INTO/Ni. However, the role of $\mathrm{Ti}^{4+}$ ions in INTO/STNO composite nanofibers can be attributed to (i) the stability of INTO for OER process in forming a stoichiometric phase ${ }^{13}$ and (ii) low valence Ti ions as seen from XPS in STNO apart from forming a defective non-stoichiometric phase, may also help in HER process. ${ }^{53-55}$ These observations are in good agreement with the HER and OER results obtained by $\mathrm{CV}$ analysis, where the NTO/GE consisting less $\mathrm{STNO}^{20}$, shows up more OER activity and 
vice versa. The performance of OER activity is highest for NTO/GE obtained at $1173 \mathrm{~K}$, having least OER Tafel slope $\left(\beta_{a}=64.8 \mathrm{mV} \cdot \mathrm{dec}^{-1}\right)$. The $\beta_{a}$ values (Table 2) obtained for NTO nanofibers are akin to the values in literature as well as better than the commercial used material, like $\mathrm{RuO}_{2},{ }^{13}$ suggest the complimentary OER kinetics of NTO nanofibers. This was also confirmed by comparing the $\beta_{a}$ of the state-of-the-art commercial $\mathrm{RuO}_{2} / \mathrm{GE}(68.4$ $\left.\mathrm{mV} \cdot \mathrm{dec}^{-1}\right)$, which suggests that the OER kinetics of NTO nanofibers run parallel to the stateof-the-art $\mathrm{RuO}_{2}$ catalyst and comparable (Table 2). In general, the OER mechanism in alkaline solution for active sites represented as $A$ on the surface of electrocatalyst is as given by ${ }^{1,13,21}$ :

$$
\begin{aligned}
& A+\mathrm{OH}^{-} \leftrightarrow \mathrm{A}-\mathrm{OH}^{-}+e^{-} \\
& \mathrm{A}-\mathrm{OH}^{-}+\mathrm{OH}^{-} \leftrightarrow \mathrm{A}-\mathrm{O}+e^{-}+\mathrm{H}_{2} \mathrm{O} \\
& \mathrm{A}-\mathrm{O}+\mathrm{OH}^{-} \leftrightarrow \mathrm{A}-\mathrm{OOH}+e^{-} \\
& A-\mathrm{OOH}+\mathrm{OH}^{-} \leftrightarrow \mathrm{A}-\mathrm{O}_{2}+e^{-}+\mathrm{H}_{2} \mathrm{O} \\
& \mathrm{A}-\mathrm{O}_{2} \leftrightarrow \mathrm{A}+\mathrm{O}_{2}
\end{aligned}
$$

Furthermore, in Figure 7 and 9, the presence of two onset potential can be attributed to the activation of two different ions (octahedral $\mathrm{Ni}$ and tetrahedral $\mathrm{Ti}$ ) at active sites $^{56,57}$ from the 
respective favourable phases. On second onset potential, the Ni rich active sites are activated, which increase the current output as seen from HER and OER CV plots. Overall, the analysis concludes that the NTO/GE obtained at $773 \mathrm{~K}$ is an excellent cathodic electrode for electrolysis in alkaline medium. In addition, the NTO/GE obtained at $1173 \mathrm{~K}$ outperforms as an anode for the same electrolysis process. Hence, these NTO nanofibers based NTO/GE electrodes have a huge potential as candidate materials for large scale production of $\mathrm{H}_{2}$ and $\mathrm{O}_{2}$ by water-splitting process.

\section{CONCLUSIONS}

NTO nanofibers with mosaic and bamboo structure were prepared by sol-gel assisted electrospinning process accompanied by pyrolysis at $773 \mathrm{~K}$ and $1173 \mathrm{~K}$, respectively. The mosaic structured NTO nanofibers which consist of high amount of SNTO and small crystallite size in comparison to the bamboo structure, show superior electrocatalytic activity for HER. The bamboo structured NTO which have lesser amount of SNTO and larger crystallite size, show dominance towards OER. The HER and OER performance of the different NTO structures may be understood based on (i) the rational affinity of $\mathrm{H}^{+}$ions towards SNTO and the large number of $\mathrm{OH}^{-}$ions adsorption at INTO (ii) the favourable composition of INTO and SNTO in different NTO nanofibers, and (iii) the conducive morphology for the diffusion of 
electrolyte to reach the preferred mating active sites. The NTO nanofibers obtained at pyrolysis soaking temperature of $773 \mathrm{~K}$ exhibits higher electrocatalytic activity for HER and is promising as a good cathode material for alkaline water-splitting. Besides, the one that is tailored at 1173 $\mathrm{K}$ outperforms as anode, with effective OER performance. In summary, SNTO/INTO nanofibers have wide potential as photo/electrochemical catalysts in water-splitting and other photo/electrocatalyst assisted applications.

\section{FUNDING INFORMATION}

This research received no specific funding from any funding agency.

\section{ACKNOWLEDGEMENTS}

Sachin Kumar is thankful to National Institute of Technology Karnataka (NITK), India, for granting the institute research fellowship. The authors are obliged to Technical Education Quality Improvement Program (TEQIPphase II) through which the PL spectrometer was procured and used for this research study. Sachin Kumar would also like to dedicate this research work in loving memories of Mrs. Saraswathamma Rangappa and Chintu, his family members, who passed away on April 2018. 


\section{REFERENCES}

1 S. Anantharaj, S. R. Ede, K. Karthick, S. S. Sankar, K. Sangeetha, P. E. Karthik and S. Kundu, Precision and correctness in the evaluation of electrocatalytic water splitting: revisiting activity parameters with a critical assessment, Energy Environ. Sci., 2018, 11, 744-771.

2 K. Zeng and D. Zhang, Recent progress in alkaline water electrolysis for hydrogen production and applications, Prog. Energy Combust. Sci., 2010, 36, 307-326.

3 Y. Lee, J. Suntivich, K. J. May, E. E. Perry and Y. Shao-Horn, Synthesis and Activities of Rutile $\mathrm{IrO}_{2}$ and $\mathrm{RuO}_{2}$ Nanoparticles for Oxygen Evolution in Acid and Alkaline Solutions, J. Phys. Chem. Lett., 2012, 3, 399-404.

4 C. G. Morales-Guio, L.-A. Stern and X. Hu, Nanostructured hydrotreating catalysts for electrochemical hydrogen evolution, Chem. Soc. Rev., 2014, 43, 6555-6569.

5 L. Han, S. Dong and E. Wang, Transition-Metal (Co, Ni, and Fe)-Based Electrocatalysts for the Water Oxidation Reaction, Adv. Mater., 2016, 28, 9266-9291.

6 M. Gong, D.-Y. Wang, C.-C. Chen, B.-J. Hwang and H. Dai, A mini review on nickel-based electrocatalysts for alkaline hydrogen evolution reaction, Nano Res., 2016, 9, 28-46.

7 Y. Xu and R. Xu, Nickel-based cocatalysts for photocatalytic hydrogen production, Appl. Surf. Sci., 2015, 351, 779-793.

8 A. Sivanantham, P. Ganesan and S. Shanmugam, Hierarchical NiCo2S4 Nanowire Arrays Supported on Ni Foam: An Efficient and Durable Bifunctional Electrocatalyst for Oxygen and Hydrogen Evolution Reactions, Adv. Funct. Mater., 2016, 26, 4661-4672.

9 M. Ledendecker, S. Krick Calderón, C. Papp, H.-P. Steinrück, M. Antonietti and M. Shalom, The Synthesis of Nanostructured Ni5P4 Films and their Use as a Non-Noble Bifunctional Electrocatalyst for Full Water Splitting, Angew. Chem., 2015, 127, 12538-12542.

10L. Elias, K. Scott and A. C. Hegde, Electrolytic Synthesis and Characterization of Electrocatalytic Ni-W Alloy, J. Mater. Eng. Perform., 2015, 24, 4182-4191.

11B. Subramanya, Y. Ullal, S. U. Shenoy, D. K. Bhat and A. C. Hegde, Novel Co-Nigraphene composite electrodes for hydrogen production, $R S C A d v$., 2015, 5, 47398-47407.

12 N. Danilovic, R. Subbaraman, D. Strmcnik, K.-C. Chang, A. P. Paulikas, V. R. Stamenkovic and N. M. Markovic, Enhancing the Alkaline Hydrogen Evolution Reaction Activity through the Bifunctionality of $\mathrm{Ni}(\mathrm{OH})_{2} /$ Metal Catalysts, Angew. Chem. Int. Ed., 2012, 51, $12495-12498$.

13C. Dong, X. Liu, X. Wang, X. Yuan, Z. Xu, W. Dong, M. Sohial Riaz, G. Li and F. Huang, Hierarchical $\mathrm{Ni} / \mathrm{NiTiO}_{3}$ derived from NiTi LDHs: a bifunctional electrocatalyst for overall water splitting, J. Mater. Chem. A, 2017, 5, 24767-24774.

14 Y. Zhao, X. Jia, G. Chen, L. Shang, G. I. N. Waterhouse, L.-Z. Wu, C.-H. Tung, D. O'Hare and $\mathrm{T}$. Zhang, Ultrafine NiO Nanosheets Stabilized by $\mathrm{TiO}_{2}$ from Monolayer NiTi-LDH 
Precursors: An Active Water Oxidation Electrocatalyst, J. Am. Chem. Soc., 2016, 138, $6517-6524$.

15 V. Thiagarajan, R. Manoharan, P. Karthikeyan, E. Nikhila, A. Hernández-Ramírez and F. J. Rodriguez-Varela, $\mathrm{Pt}$ nanoparticles supported on $\mathrm{NiTiO}_{3} / \mathrm{C}$ as electrocatalyst towards high performance Methanol Oxidation Reaction, Int. J. Hydrog. Energy, 2017, 42, 9795-9805.

16M. A. Ruiz-Preciado, A. A. F. Caballero, A. M. Robledo and A. Morales-Acevedo, Nanostructured $\mathrm{NiTiO}_{3}$ as a Catalytic Material for Methanol Electrochemical Oxidation in Alkaline Conditions, J. Electrochem. Soc., 2018, 165, H84-H90.

17 J. B. Bellam, M. A. Ruiz-Preciado, M. Edely, J. Szade, A. Jouanneaux and A. H. Kassiba, Visible-light photocatalytic activity of nitrogen-doped $\mathrm{NiTiO}_{3}$ thin films prepared by a cosputtering process, $R S C A d v$., 2015, 5, 10551-10559.

18 S. A. Rawool, M. R. Pai, A. M. Banerjee, A. Arya, R. S. Ningthoujam, R. Tewari, R. Rao, B. Chalke, P. Ayyub, A. K. Tripathi and S. R. Bharadwaj, pn Heterojunctions in $\mathrm{NiO}^{-\mathrm{TiO}_{2}}$ composites with type-II band alignment assisting sunlight driven photocatalytic $\mathrm{H}_{2}$ generation, Appl. Catal. B Environ., 2018, 221, 443-458.

19Y. Zeng, Y. Wang, J. Chen, Y. Jiang, M. Kiani, B. Li and R. Wang, Fabrication of highactivity hybrid $\mathrm{NiTiO}_{3} / \mathrm{g}-\mathrm{C}_{3} \mathrm{~N}_{4}$ heterostructured photocatalysts for water splitting to enhanced hydrogen production, Ceram. Int., 2016, 42, 12297-12305.

20B. S. Kumar, A. M. Shanmugharaj, S. K. Kalpathy and S. Anandhan, Some new observations on the structural and phase evolution of nickel titanate nanofibers, Ceram. Int., $2017, \mathbf{4 3}, 6845-6857$.

21 M. Li, H. Liu, T. Lv and M. Ding, Synergistic effect of the valence bond environment and exposed crystal facets of the $\mathrm{TiO}_{2} / \mathrm{SnS}_{2}$ heterojunction for achieving enhanced electrocatalytic oxygen evolution, J. Mater. Chem. A, 2018, 6, 3488-3499.

22 Y. Fujioka, J. Frantti, A. Puretzky and G. King, Raman Study of the Structural Distortion in the $\mathrm{Ni}_{1-\mathrm{x}} \mathrm{Co}_{\mathrm{x}} \mathrm{TiO}_{3}$ Solid Solution, Inorg. Chem., 2016, 55, 9436-9444.

23 M. A. R. Preciado, A. Kassiba, A. Morales-Acevedo and M. Makowska-Janusik, Vibrational and electronic peculiarities of $\mathrm{NiTiO}_{3}$ nanostructures inferred from first principle calculations, $R S C A d v$., 2015, 5, 17396-17404.

24R. A. Pontes Ribeiro, S. R. de Lazaro and C. Gatti, The role of exchange-correlation functional on the description of multiferroic properties using density functional theory: the $\mathrm{ATiO}_{3}(\mathrm{~A}=\mathrm{Mn}, \mathrm{Fe}, \mathrm{Ni})$ case study, RSC Adv., 2016, 6, 101216-101225.

25 M.-W. Li, J.-P. Yuan, X.-M. Gao, E.-Q. Liang and C.-Y. Wang, Structure and optical absorption properties of $\mathrm{NiTiO}_{3}$ nanocrystallites, Appl. Phys. A, 2016, 122, 725.

26X. Zhang, B. Lu, R. Li, C. Fan, Z. Liang and P. Han, Structural, electronic and optical properties of Ilmenite $\mathrm{ATiO}_{3}(\mathrm{~A}=\mathrm{Fe}, \mathrm{Co}, \mathrm{Ni})$, Mater. Sci. Semicond. Process., 2015, 39, 616. 
27 S. Challagulla, K. Tarafder, R. Ganesan and S. Roy, All that Glitters Is Not Gold: A Probe into Photocatalytic Nitrate Reduction Mechanism over Noble Metal Doped and Undoped $\mathrm{TiO}_{2}$, J. Phys. Chem. C, 2017, 121, 27406-27416.

28 A. Aytimur, S. Koçyiğit, İ. Uslu, Ş. Durmuşoğlu and A. Akdemir, Fabrication and characterization of bismuth oxide-holmia nanofibers and nanoceramics, Curr. Appl. Phys., 2013, 13, 581-586.

29B. S. Kumar, V. C. Gudla, R. Ambat, S. K. Kalpathy and S. Anandhan, Graphene nanoclusters embedded nickel cobaltite nanofibers as multifunctional electrocatalyst for glucose sensing and water-splitting applications, Ceram. Int., 2019, Online.

30E. Rafiee, M. Farzam, M. A. Golozar and A. Ashrafi, An Investigation on Dislocation Density in Cold-Rolled Copper Using Electrochemical Impedance Spectroscopy, Int. Sch. Res. Not. Corros., 2013, 2013, 6.

31 M. A. Ruiz-Preciado, A. Kassiba, A. Gibaud and A. Morales-Acevedo, Comparison of nickel titanate $\left(\mathrm{NiTiO}_{3}\right)$ powders synthesized by sol-gel and solid state reaction, Mater. Sci. Semicond. Process., 2015, 37, 171-178.

32 V. D'Ippolito, G. B. Andreozzi, D. Bersani and P. P. Lottici, Raman fingerprint of chromate, aluminate and ferrite spinels, J. Raman Spectrosc., 2015, 46, 1255-1264.

33R. Vijayalakshmi and V. Rajendran, Synthesis, structural characterisation and optical properties of nanoparticles of $\mathrm{MTiO}_{3}(\mathrm{M}=\mathrm{Ni}$ and $\mathrm{Co})$ obtained by the chemical method, Int. J. Nanoparticles, 2013, 6, 28.

34K. Yoshimatsu, H. Mashiko, N. Umezawa, K. Horiba, H. Kumigashira and A. Ohtomo, Electronic Structures and Photoanodic Properties of Ilmenite-type $\mathrm{MTiO}_{3}$ Epitaxial Films (M = Mn, Fe, Co, Ni), J. Phys. Chem. C, 2017, 121, 18717-18724.

35 A. M. Banerjee, M. R. Pai, A. Arya and S. R. Bharadwaj, Photocatalytic $\mathrm{H}_{2}$ generation over $\mathrm{In}_{2} \mathrm{TiO}_{5}$, Ni substituted $\mathrm{In}_{2} \mathrm{TiO}_{5}$ and $\mathrm{NiTiO}_{3}$ - a combined theoretical and experimental study, RSC Adv., 2015, 5, 61218-61229.

36C. Xin, Y. Wang, Y. Sui, Y. Wang, X. Wang, K. Zhao, Z. Liu, B. Li and X. Liu, Electronic, magnetic and multiferroic properties of magnetoelectric $\mathrm{NiTiO}_{3}$, J. Alloys Compd., 2014, 613, 401-406.

37 K. K. Naik, A. Gangan, B. Chakraborty, S. K. Nayak and C. S. Rout, Enhanced Nonenzymatic Glucose-Sensing Properties of Electrodeposited $\mathrm{NiCo}_{2} \mathrm{O}_{4}-\mathrm{Pd}$ Nanosheets: Experimental and DFT Investigations, ACS Appl. Mater. Interfaces, 2017, 9, 23894-23903.

38 B. Amin, R. Khenata, A. Bouhemadou, I. Ahmad and M. Maqbool, Opto-electronic response of spinels $\mathrm{MgAl}_{2} \mathrm{O}_{4}$ and $\mathrm{MgGa}_{2} \mathrm{O}_{4}$ through modified Becke-Johnson exchange potential, Phys. B Condens. Matter, 2012, 407, 2588-2592.

39B. Amin, I. Ahmad, M. Maqbool, S. Goumri-Said and R. Ahmad, Ab initio study of the bandgap engineering of $\mathrm{Al}_{1_{-x}} \mathrm{Ga}_{\mathrm{x}} \mathrm{N}$ for optoelectronic applications, J. Appl. Phys., 2011, 109, 023109. 
40 G. Yang, W. Chang and W. Yan, Fabrication and characterization of $\mathrm{NiTiO}_{3}$ nanofibers by sol-gel assisted electrospinning, J. Sol-Gel Sci. Technol., 2014, 69, 473-479.

41 B. S. Kumar, V. C. Gudla, R. Ambat, S. K. Kalpathy and S. Anandhan, A Mechanistic Study on the Structure Formation of $\mathrm{NiCO}_{2} \mathrm{O}_{4}$ Nanofibers Decorated with In Situ Formed Graphene-Like Structures, J. Inorg. Organomet. Polym. Mater., 2018, 1-16.

42 Y. Qu, W. Zhou, Z. Ren, S. Du, X. Meng, G. Tian, K. Pan, G. Wang and H. Fu, Facile preparation of porous $\mathrm{NiTiO}_{3}$ nanorods with enhanced visible-light-driven photocatalytic performance, J. Mater. Chem., 2012, 22, 16471-16476.

43 D. N. Braski, N. R. Osborne and J. M. Zurbuchen, Xps Study of Ni-Fe Manganite Thermistor Material, MRS Online Proc. Libr. Arch., 1994, 360, 139-144.

44Leinen D., Fernández A., Espinós J. P. and González-Elipe A. R., XPS and ISS study of $\mathrm{NiTiO}_{3}$ and $\mathrm{PbTiO}_{3}$ subjected to low-energy ion bombardment. I. Influence of the type of ion $\left(\mathrm{Ar}^{+}\right.$and $\left.\mathrm{O}_{2}^{+}\right)$, Surf. Interface Anal., 2004, 20, 941-948.

45 M. A. Arillo, M. L. López, C. Pico, M. L. Veiga, A. Jiménez-López and E. RodríguezCastellón, Surface characterisation of spinels with Ti(IV) distributed in tetrahedral and octahedral sites, J. Alloys Compd., 2001, 317-318, 160-163.

46 M. C. Capel-Sanchez, J. M. Campos-Martin, J. L. G. Fierro, M. P. de Frutos and A. P. Polo, Effective alkene epoxidation with dilute hydrogen peroxide on amorphous silica-supported titanium catalysts, Chem. Commun., 2000, 0, 855-856.

47T. Varga, T. C. Droubay, M. E. Bowden, P. Nachimuthu, V. Shutthanandan, T. B. Bolin, W. A. Shelton and S. A. Chambers, Epitaxial growth of $\mathrm{NiTiO}_{3}$ with a distorted ilmenite structure, Thin Solid Films, 2012, 520, 5534-5541.

48 B. Bharti, S. Kumar, H.-N. Lee and R. Kumar, Formation of oxygen vacancies and $\mathrm{Ti}^{3+}$ state in $\mathrm{TiO}_{2}$ thin film and enhanced optical properties by air plasma treatment, Sci. Rep., 2016, 6, 32355 .

49G. George, L. Elias, A. C. Hegde and S. Anandhan, Morphological and structural characterisation of sol-gel electrospun $\mathrm{Co}_{3} \mathrm{O}_{4}$ nanofibres and their electro-catalytic behaviour, RSC Adv., 2015, 5, 40940-40949.

50 Y. Ullal and A. C. Hegde, Electrodeposition and electro-catalytic study of nanocrystalline Ni-Fe alloy, Int. J. Hydrog. Energy, 2014, 39, 10485-10492.

51 B. E. Conway and B. V. Tilak, Interfacial processes involving electrocatalytic evolution and oxidation of $\mathrm{H}_{2}$, and the role of chemisorbed H, Electrochimica Acta, 2002, 47, 3571-3594.

52 Y. Choquette, L. Brossard, A. Lasia and H. Menard, Study of the Kinetics of Hydrogen Evolution Reaction on Raney Nickel Composite-Coated Electrode by AC Impedance Technique, J. Electrochem. Soc., 1990, 137, 1723-1730.

53 J. Swaminathan, R. Subbiah and V. Singaram, Defect-Rich Metallic Titania $\left(\mathrm{TiO}_{1.23}\right)$-An Efficient Hydrogen Evolution Catalyst for Electrochemical Water Splitting, ACS Catal., 2016, 6, 2222-2229. 
54F. Zuo, L. Wang, T. Wu, Z. Zhang, D. Borchardt and P. Feng, Self-Doped $\mathrm{Ti}^{3+}$ Enhanced Photocatalyst for Hydrogen Production under Visible Light, J. Am. Chem. Soc., 2010, 132, 11856-11857.

55Q. Lu, G. S. Hutchings, W. Yu, Y. Zhou, R. V. Forest, R. Tao, J. Rosen, B. T. Yonemoto, Z. Cao, H. Zheng, J. Q. Xiao, F. Jiao and J. G. Chen, Highly porous non-precious bimetallic electrocatalysts for efficient hydrogen evolution, Nat. Commun., 2015, 6, 6567.

56P. Rasiyah, A. C. C. Tseung and D. B. Hibbert, A Mechanistic Study of Oxygen Evolution on $\mathrm{NiCo}_{2} \mathrm{O}_{4} \mathrm{I}$. Formation of Higher Oxides, J. Electrochem. Soc., 1982, 129, 1724-1727.

57P. Rasiyah and A. C. C. Tseung, A Mechanistic Study of Oxygen Evolution on $\mathrm{NiCo}_{2} \mathrm{O}_{4} \mathrm{II}$ . Electrochemical Kinetics, J. Electrochem. Soc., 1983, 130, 2384-2386.

58 L.-A. Stern, L. Feng, F. Song and X. Hu, Ni 2 P as a Janus catalyst for water splitting: the oxygen evolution activity of $\mathrm{Ni}_{2} \mathrm{P}$ nanoparticles, Energy Environ. Sci., 2015, 8, 2347-2351.

59 X. Li, L. Zhang, M. Huang, S. Wang, X. Li and H. Zhu, Cobalt and nickel selenide nanowalls anchored on graphene as bifunctional electrocatalysts for overall water splitting, J. Mater. Chem. A, 2016, 4, 14789-14795.

60X. Gao, H. Zhang, Q. Li, X. Yu, Z. Hong, X. Zhang, C. Liang and Z. Lin, Hierarchical $\mathrm{NiCo}_{2} \mathrm{O}_{4}$ Hollow Microcuboids as Bifunctional Electrocatalysts for Overall Water-Splitting, Angew. Chem. Int. Ed., 2016, 55, 6290-6294.

61 Y. Pan, Y. Liu, J. Zhao, K. Yang, J. Liang, D. Liu, W. Hu, D. Liu, Y. Liu and C. Liu, Monodispersed nickel phosphide nanocrystals with different phases: synthesis, characterization and electrocatalytic properties for hydrogen evolution, J. Mater. Chem. A, $2015,3,1656-1665$.

62X. Yan, L. Tian and X. Chen, Crystalline/amorphous Ni/NiO core/shell nanosheets as highly active electrocatalysts for hydrogen evolution reaction, J. Power Sources, 2015, 300, 336343.

63Q. Zhang, Y. Wang, Y. Wang, A. M. Al-Enizi, A. A. Elzatahry and G. Zheng, Myriophyllum-like hierarchical TiN@ $\mathrm{Ni}_{3} \mathrm{~N}$ nanowire arrays for bifunctional water splitting catalysts, J. Mater. Chem. A, 2016, 4, 5713-5718. 


\section{LIST OF TABLES}

Table 1: Crystallite size, dislocation density, HER, and OER parameters of NTO nanofibers (INTO/SNTO nanoparticles) developed at different

pyrolysis temperature.

\begin{tabular}{|c|c|c|c|c|c|c|c|c|c|c|}
\hline \multirow[t]{2}{*}{$\begin{array}{c}\text { Calcination } \\
\text { temperature, } \\
\mathbf{T} \\
\text { (K) }\end{array}$} & \multicolumn{2}{|c|}{$\begin{array}{c}\text { Crystallite } \\
\text { size obtained } \\
\text { from } \\
\text { Williamson- } \\
\text { Hall plot }{ }^{20}, D \\
\text { (nm) }\end{array}$} & \multicolumn{2}{|c|}{$\begin{array}{l}\text { Dislocation } \\
\text { density, } \delta \\
\quad\left(\times 10^{11}\right. \\
\left.\text { lines } \cdot \mathbf{c m}^{-2}\right)\end{array}$} & \multirow[t]{2}{*}{$\begin{array}{c}\text { Cathodic } \\
\text { peak } \\
\text { current at } \\
1.6 \mathrm{~V} \\
(\mathrm{~mA})\end{array}$} & \multicolumn{2}{|c|}{$\begin{array}{c}\text { Onset potential of } \\
\mathrm{H}_{2} \text { evolution, } \text { E }_{\text {we }} \text { vs. SCE } \\
\text { (V) }\end{array}$} & \multirow[t]{2}{*}{$\begin{array}{c}\text { Anodic } \\
\text { peak } \\
\text { current } \\
\text { at } 0.75 \mathrm{~V} \\
(\mathrm{~mA})\end{array}$} & \multicolumn{2}{|c|}{$\begin{array}{l}\text { Onset potential of } \\
\text { O}_{2} \text { evolution, } \\
\text { Ewe vs. SCE } \\
\text { (V) }\end{array}$} \\
\hline & INTO & SNTO & INTO & SNTO & & $\begin{array}{c}\text { Tetrahedral } \\
T i\end{array}$ & $\begin{array}{c}\text { Octahedral } \\
\mathrm{Ni}\end{array}$ & & $\begin{array}{c}\text { Tetrahedral } \\
\mathrm{Ti}\end{array}$ & $\begin{array}{c}\text { Octahedral } \\
\mathrm{Ni}\end{array}$ \\
\hline 773 & 24.20 & 13.01 & 1.71 & 5.91 & -46.4 & -0.37 & -0.69 & 42.6 & 0.19 & 0.382 \\
\hline 973 & 24.33 & 38.63 & 1.69 & 0.67 & -18.5 & -0.38 & -0.74 & 125 & 0.19 & 0.336 \\
\hline 1173 & 33.75 & 83.54 & 0.88 & 0.14 & -11.6 & -0.38 & -0.82 & 211 & 0.18 & 0.296 \\
\hline
\end{tabular}


Table 2: Comparison of synthesis, morphology, HER, and OER parameters with some reported mono/bifunctional electrocatalysts.

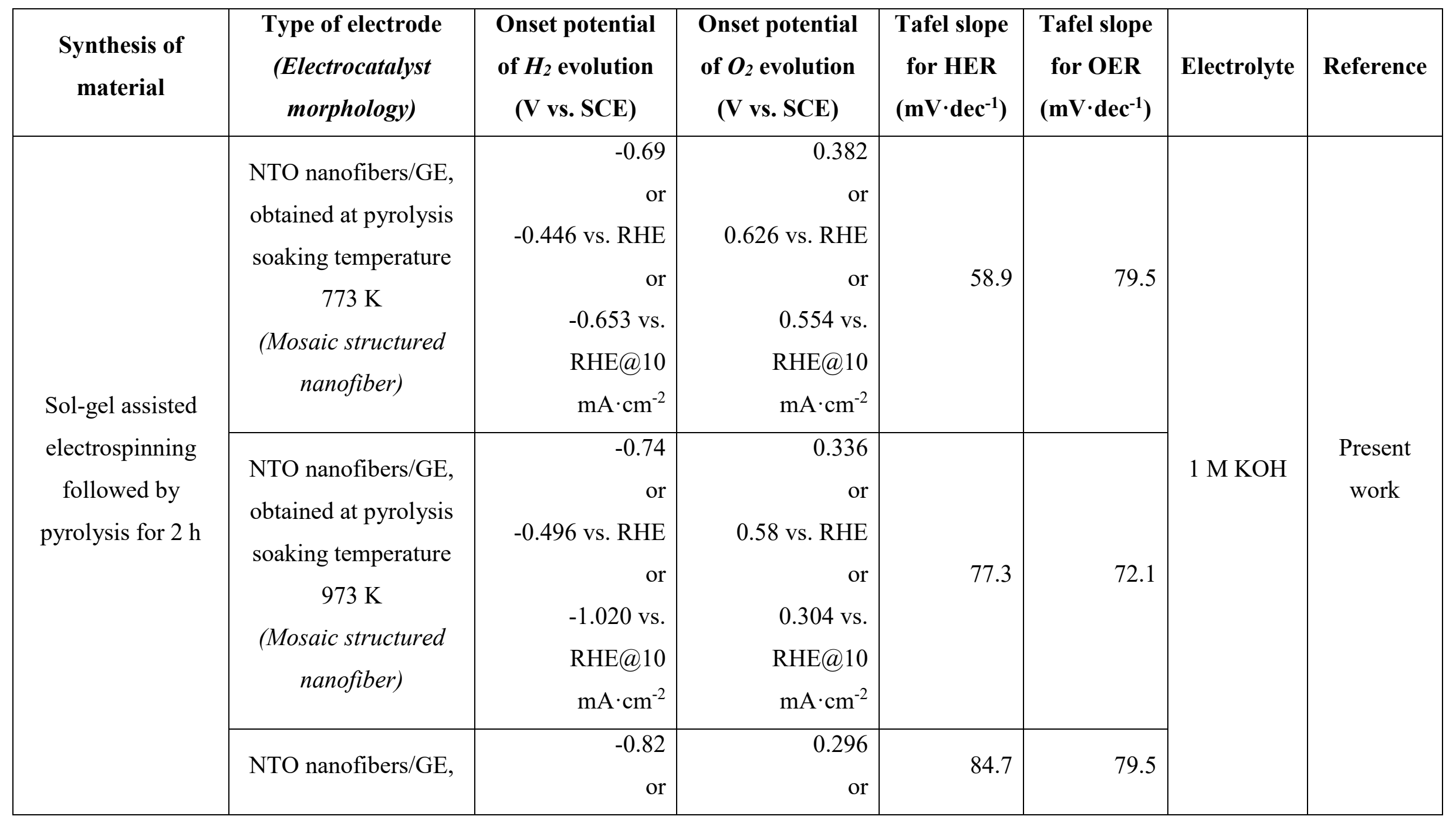




\begin{tabular}{|c|c|c|c|c|c|c|c|}
\hline & $\begin{array}{c}\text { obtained at pyrolysis } \\
\text { soaking temperature } \\
1173 \mathrm{~K} \\
\text { (Bamboo structured } \\
\text { nanofiber) }\end{array}$ & $\begin{array}{r}-0.576 \text { vs. RHE } \\
\text { or } \\
-1.263 \text { vs. } \\
\text { RHE@10 } 10 \\
\mathrm{~mA} \cdot \mathrm{cm}^{-2}\end{array}$ & $\begin{array}{r}0.54 \text { vs. RHE } \\
\text { or } \\
0.266 \mathrm{vs} . \\
\mathrm{RHE} @ 10 \\
\mathrm{~mA} \cdot \mathrm{cm}^{-2}\end{array}$ & & & & \\
\hline $\begin{array}{l}\text { As procured in the } \\
\text { State-of-the-art } \\
\text { (Figure S7a and b, } \\
\text { ESI) }\end{array}$ & $\begin{array}{l}\text { Commercial Pt/C/GE } \\
\text { (Powder, Pt particle } \\
\text { size }<5 \mathrm{~nm} \text { ) }\end{array}$ & $\begin{array}{r}-0.935 \\
\text { or } \\
-0.691 \mathrm{vs} . \mathrm{RHE} \\
\text { or } \\
-1.072 \mathrm{vs} . \\
\mathrm{RHE} @ 10 \\
\mathrm{~mA} \cdot \mathrm{cm}^{-2}\end{array}$ & - & 117.4 & - & $1 \mathrm{M} \mathrm{KOH}$ & \\
\hline $\begin{array}{l}\text { As procured in the } \\
\text { State-of-the-art } \\
\text { (Figure S7c and d, } \\
\text { ESI) }\end{array}$ & $\begin{array}{c}\text { Commercial } \mathrm{RuO}_{2} / \mathrm{GE} \\
\text { (Powder) }\end{array}$ & - & $\begin{array}{r}0.417 \\
\text { or } \\
0.661 \mathrm{vs} . \mathrm{RHE} \\
\text { or } \\
0.751 \mathrm{vs} . \\
\mathrm{RHE} @ 10 \\
\mathrm{~mA} \cdot \mathrm{cm}^{-2}\end{array}$ & - & 68.4 & $1 \mathrm{M} \mathrm{KOH}$ & \\
\hline $\begin{array}{l}\text { Sol-gel assisted } \\
\text { electrospinning }\end{array}$ & NCO nanofibers/GE, & $\begin{array}{r}-0.781 \\
\text { or }\end{array}$ & $\begin{array}{r}0.491 \\
\text { or }\end{array}$ & 37.6 & 67.0 & $1 \mathrm{M} \mathrm{NaOH}$ & 29 \\
\hline
\end{tabular}




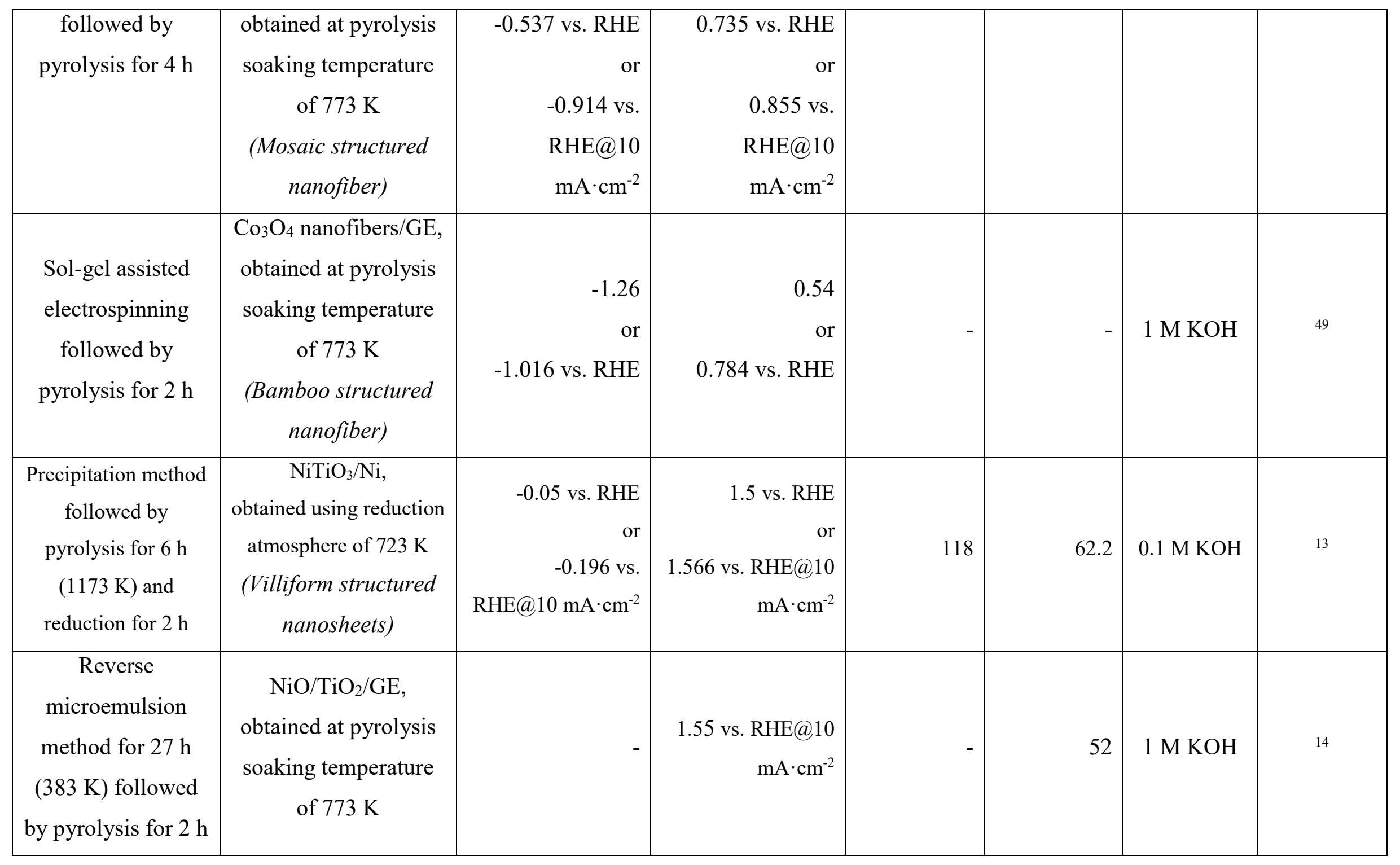




\begin{tabular}{|c|c|c|c|c|c|c|c|}
\hline & $\begin{array}{l}\text { (Monolayer } \\
\text { nanosheets) }\end{array}$ & & & & & & \\
\hline $\begin{array}{l}\text { Solid-state reaction } \\
\text { followed by } \\
\text { pyrolysis for } 1 \mathrm{~h}\end{array}$ & $\begin{array}{c}\mathrm{Ni}_{2} \mathrm{P} / \mathrm{GE}, \\
\text { obtained at using } \mathrm{N}_{2} \\
\text { atmosphere of } 523 \mathrm{~K} \\
\text { (Nanoparticles) }\end{array}$ & $\begin{array}{r}-0.221 \mathrm{vs} . \\
\text { RHE@10 } \mathrm{mA} \cdot \mathrm{cm}^{-2}\end{array}$ & $\begin{array}{r}1.45 \text { vs. RHE } \\
\text { or } \\
1.52 \text { vs. RHE@10 } \\
\mathrm{mA} \cdot \mathrm{cm}^{-2}\end{array}$ & - & 47 & $1 \mathrm{M} \mathrm{KOH}$ & 58 \\
\hline $\begin{array}{l}\text { Electrodeposition } \\
\text { followed by } \\
\text { selenization } \\
\text { (Graphene/Ni mesh } \\
\text { by chemical vapour } \\
\text { deposition) }\end{array}$ & $\begin{array}{c}\text { NiSe/Graphene/Ni } \\
\text { mesh } \\
\text { (Nanowalls) }\end{array}$ & - & $\begin{array}{r}1.6 \text { vs. RHE } \\
\text { or } \\
1.66 \text { vs. RHE@10 } \\
\mathrm{mA} \cdot \mathrm{cm}^{-2}\end{array}$ & - & 83.4 & $1 \mathrm{M} \mathrm{KOH}$ & 59 \\
\hline $\begin{array}{c}\text { Hydrothermal } \\
\text { synthesis for } 8 \mathrm{~h}\end{array}$ & $\begin{array}{c}\mathrm{NiCo}_{2} \mathrm{~S}_{4} / \mathrm{Ni} \text { foam, } \\
\text { obtained at } 393 \mathrm{~K} \\
\text { (Nanowires) }\end{array}$ & $\begin{array}{r}-0.21 \mathrm{vs} \text { RHE } \\
\text { or } \\
-0.310 \mathrm{vs} . \\
\text { RHE@10 } \mathrm{mA} \cdot \mathrm{cm}^{-2}\end{array}$ & $\begin{array}{r}1.5 \text { vs. RHE } \\
\text { or } \\
1.57 \text { vs. RHE@10 } \\
\mathrm{mA} \cdot \mathrm{cm}^{-2}\end{array}$ & 58.9 & 40.1 & $0.1 \mathrm{M} \mathrm{KOH}$ & 8 \\
\hline $\begin{array}{c}\text { Solvothermal } \\
\text { process followed } \\
\text { by pyrolysis for } 2 \mathrm{~h}\end{array}$ & $\begin{array}{c}\text { Hierarchical } \\
\mathrm{NiCo}_{2} \mathrm{O}_{4} / \mathrm{Ni} \text { foam, }\end{array}$ & $\begin{array}{l}-0.110 \mathrm{vs} . \\
\text { RHE@10 } \\
\mathrm{mA} \cdot \mathrm{cm}^{-2}\end{array}$ & $\begin{array}{r}1.52 \text { vs. RHE@10 } \\
\mathrm{mA} \cdot \mathrm{cm}^{-2}\end{array}$ & 49.7 & 53.0 & $1 \mathrm{M} \mathrm{NaOH}$ & 60 \\
\hline
\end{tabular}




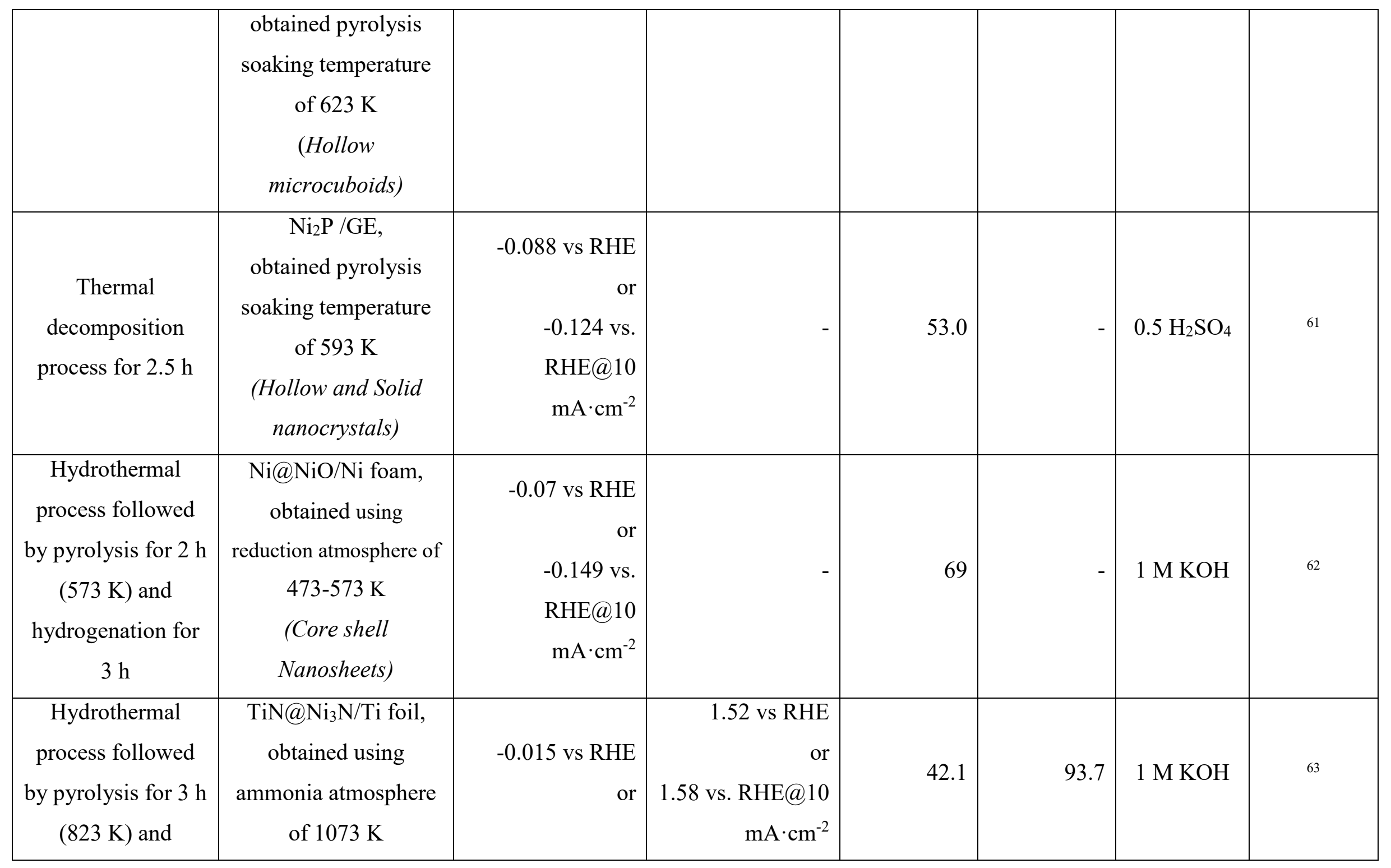




\begin{tabular}{|c|c|r|l|l|l|}
\hline ammonisation for 2 & (Myriophyllum-like & $-0.021 \mathrm{vs}$ \\
$\mathrm{h}$ & nanowires) & RHE@10 \\
& $\mathrm{mA} \cdot \mathrm{cm}^{-2}$ & & & & \\
& & & & & \\
\hline
\end{tabular}

$\mathrm{E}_{\mathrm{RHE}}=\mathrm{E}_{\mathrm{SCE}}+0.244 \mathrm{~V}$, Onset potential of HER $=$ overpotential $+0 \mathrm{~V}$, Onset potential of OER = overpotential + 1.23 V, GE: glassy carbon/graphite

electrode. 


\section{CAPTION TO FIGURES}

Figure 1: Schematic showing test cell set-up for electrochemical studies.

Figure 2: HRTEM of NTO nanofibers obtained at different pyrolysis soaking temperatures (a)

$773 \mathrm{~K}$, (b) $973 \mathrm{~K}$, and (c) $1173 \mathrm{~K}$. Inset figures are the lattice fringes and indexed SAED patterns of the polycrystalline NTO nanofibers in corresponding samples.

Figure 3: (a) UV-vis-NIR absorption spectra, (b) Raman spectra, (c) PL emission spectra of NTO nanofibers obtained at different pyrolysis soaking temperatures, and (d) CIE 1931 chromaticity diagram.

Figure 4: DOS calculated by DFT analysis for (a) INTO and (b) SNTO. Inset figures are the corresponding unit cells of INTO and SNTO phases.

Figure 5: Comparison of optical conductivity of INTO and SNTO acquired by DFT analysis.

Figure 6: XPS depth profiling analysis of NTO nanofibers obtained at pyrolysis soaking temperature of $773 \mathrm{~K}$. (a) survey spectra, (b) high-resolution spectra for $\mathrm{O} 1 \mathrm{~s}$, (c) highresolution spectra for $\mathrm{Ni} 2 p$, and (d) high-resolution spectra for Ti $2 p$ (inset figure: spin-orbit splitting for $\mathrm{Ti}^{3+}$ ion). S: surface, D1: depth 1- after first $\mathrm{Ar}^{+}$ion etching, and D2: depth 2. The 
deconvoluted peaks in each individual graph are representative and similar deconvoluted peaks exists in all the three high-resolution spectra of corresponding graph.

Figure 7: CV curves for HER analysis using NTO/GE developed at different pyrolysis soaking temperatures.

Figure 8: CP stability responses attained by NTO/GE developed at different pyrolysis soaking temperatures, for HER. Inset figure: $\mathrm{H}_{2}$ liberated for $300 \mathrm{~s}$ for corresponding NTO/GE.

Figure 9: CV curves for OER analysis using NTO/GE developed at different pyrolysis soaking temperatures.

Figure 10: $\mathrm{CP}$ stability responses attained by NTO/GE developed at different pyrolysis soaking temperatures, for OER. Inset figure: $\mathrm{O}_{2}$ liberated for $300 \mathrm{~s}$ for corresponding NTO/GE.

Figure 11: Comparison of Tafel polarisation plots and slopes, for HER and OER, of NTO/GE developed at different pyrolysis soaking temperatures. 


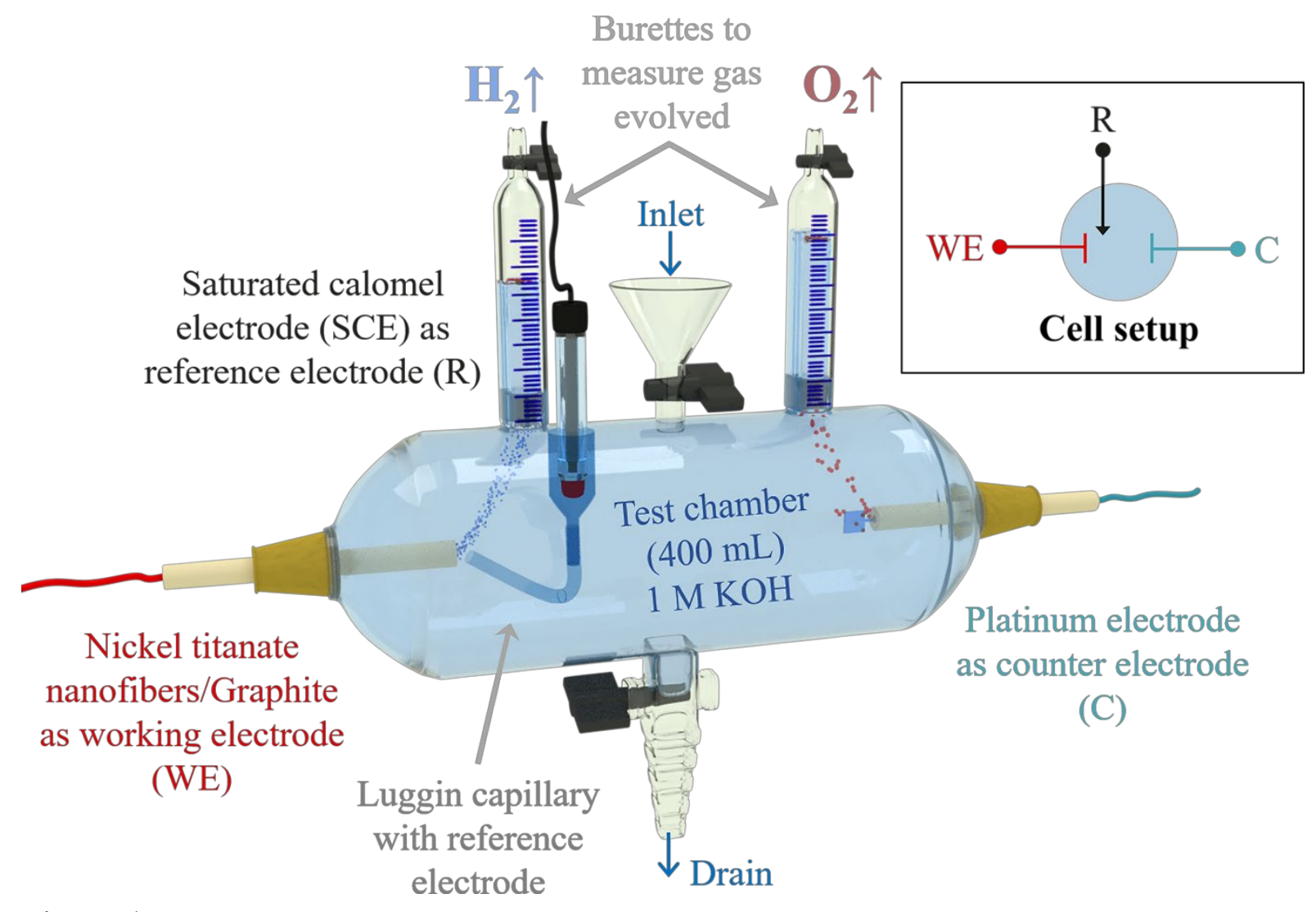

Figure 1 


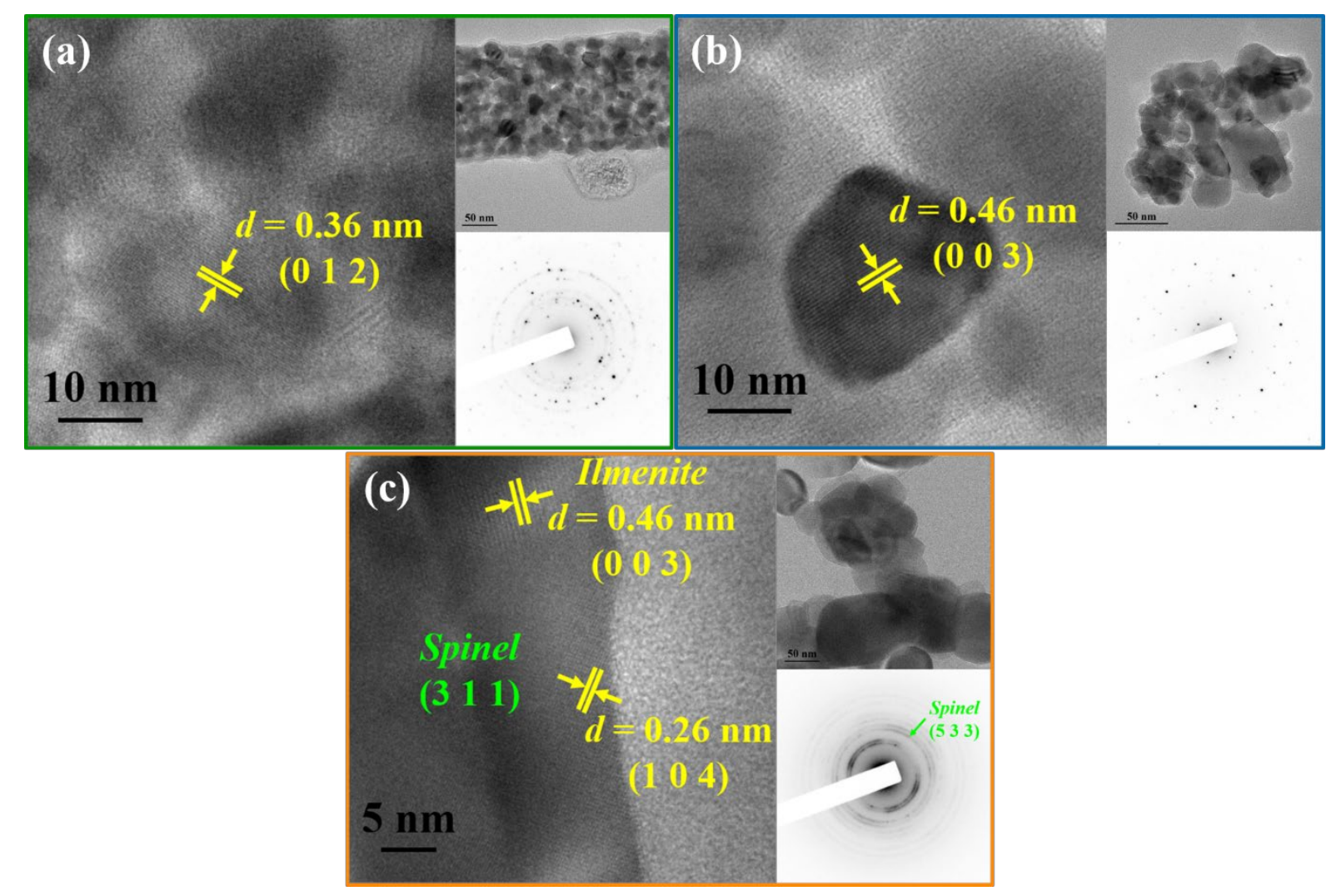

Figure 2 
(a)

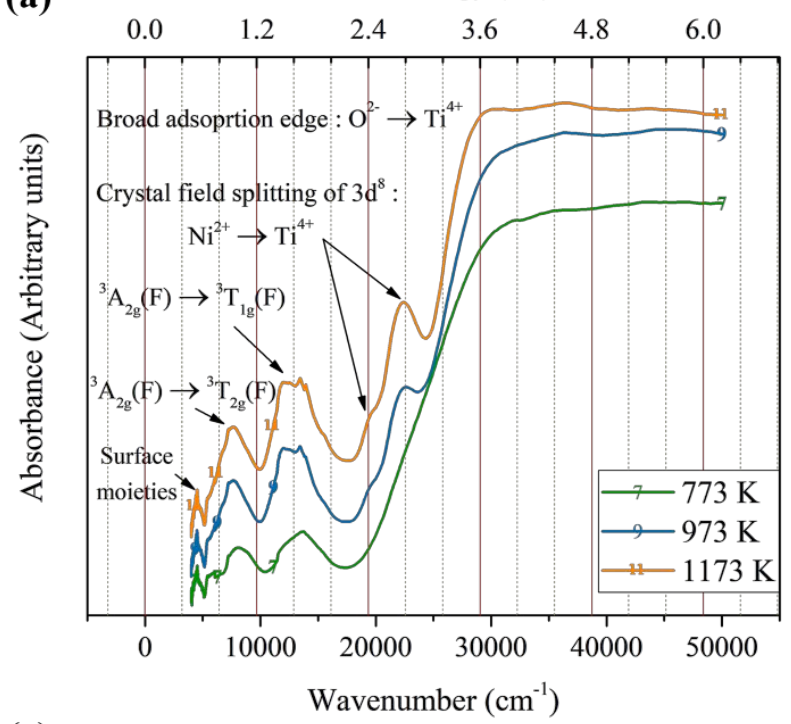

(c)
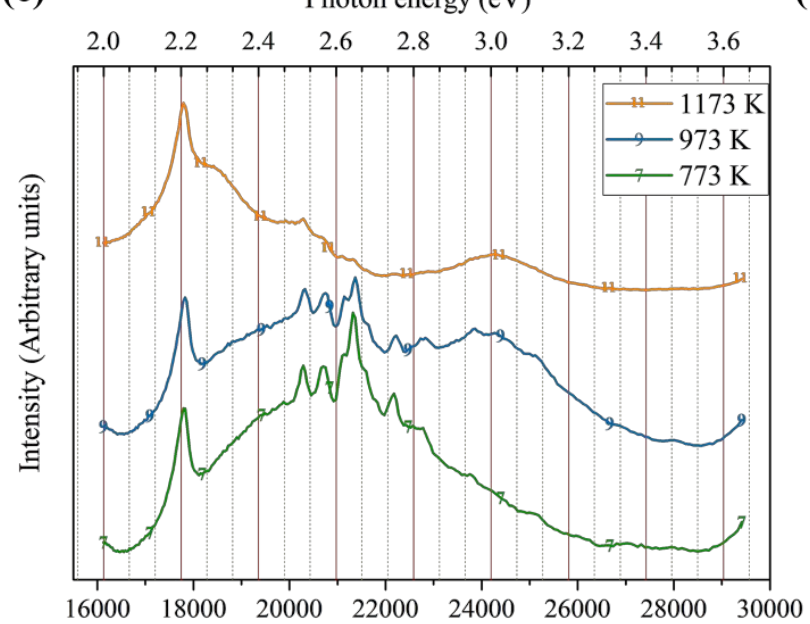

Wavenumber $\left(\mathrm{cm}^{-1}\right)$ (b)

Photon energy (eV)

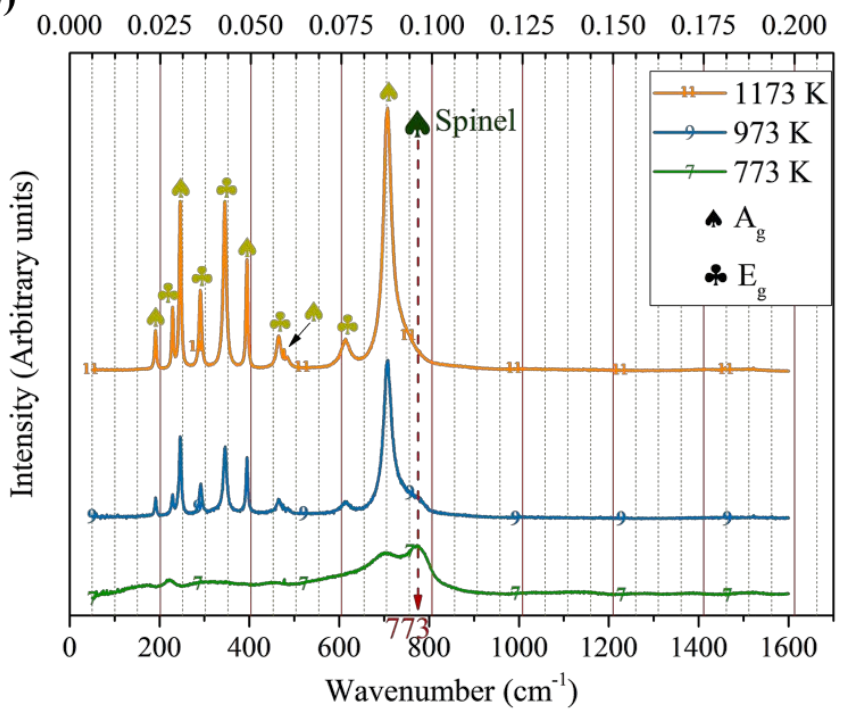

(d)

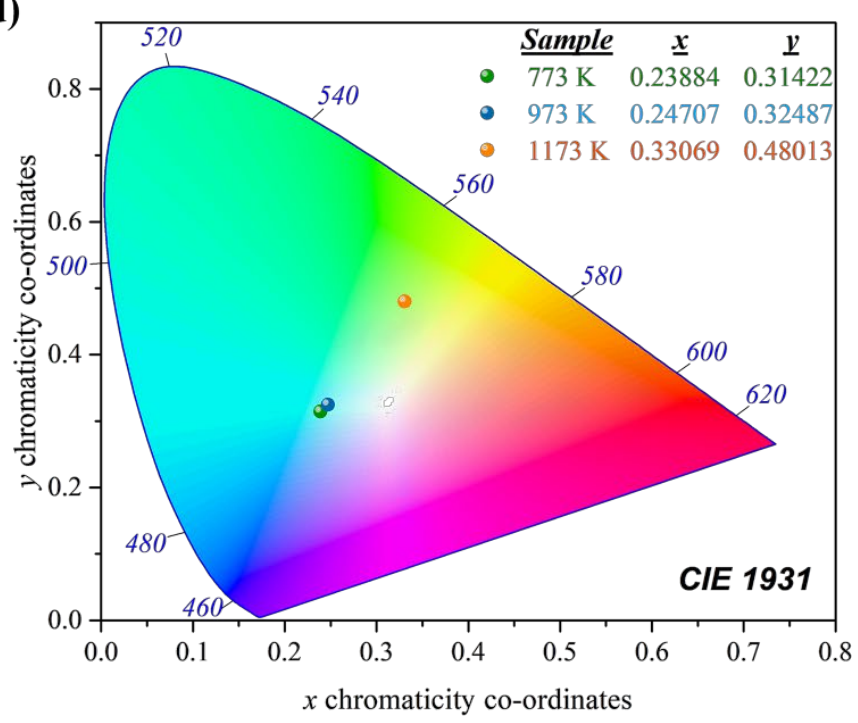

Figure 3 


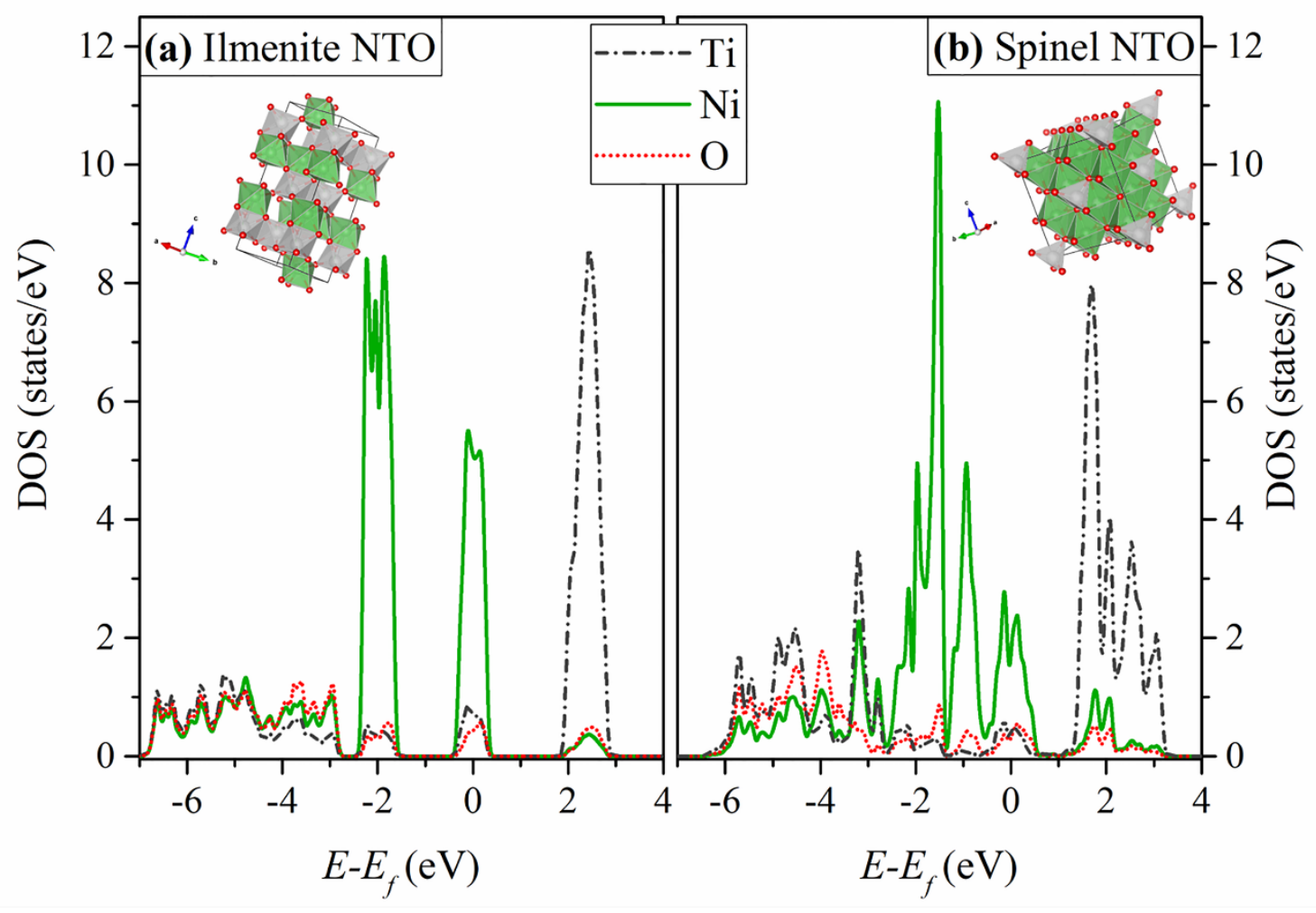

Figure 4 


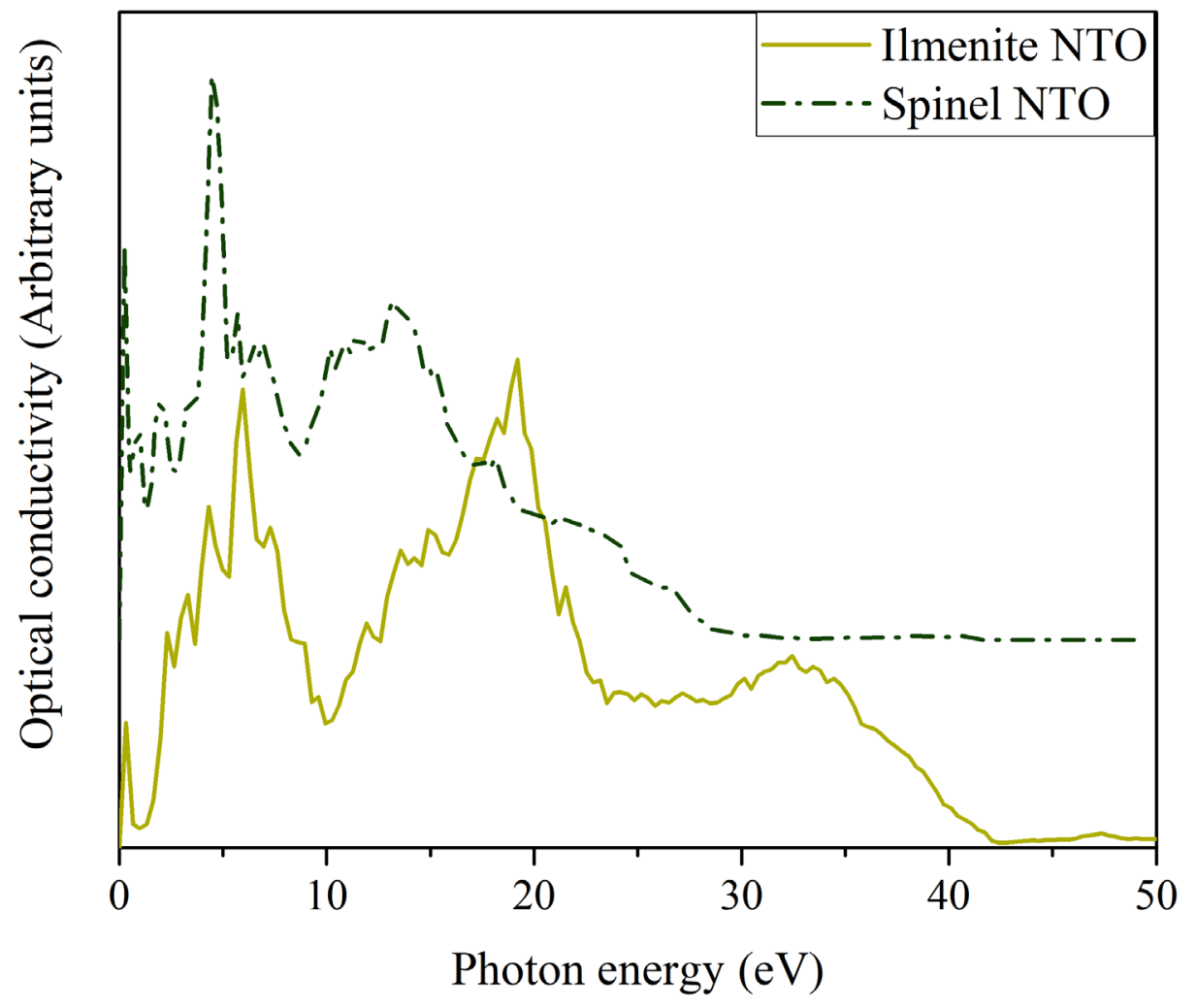

Figure 5 

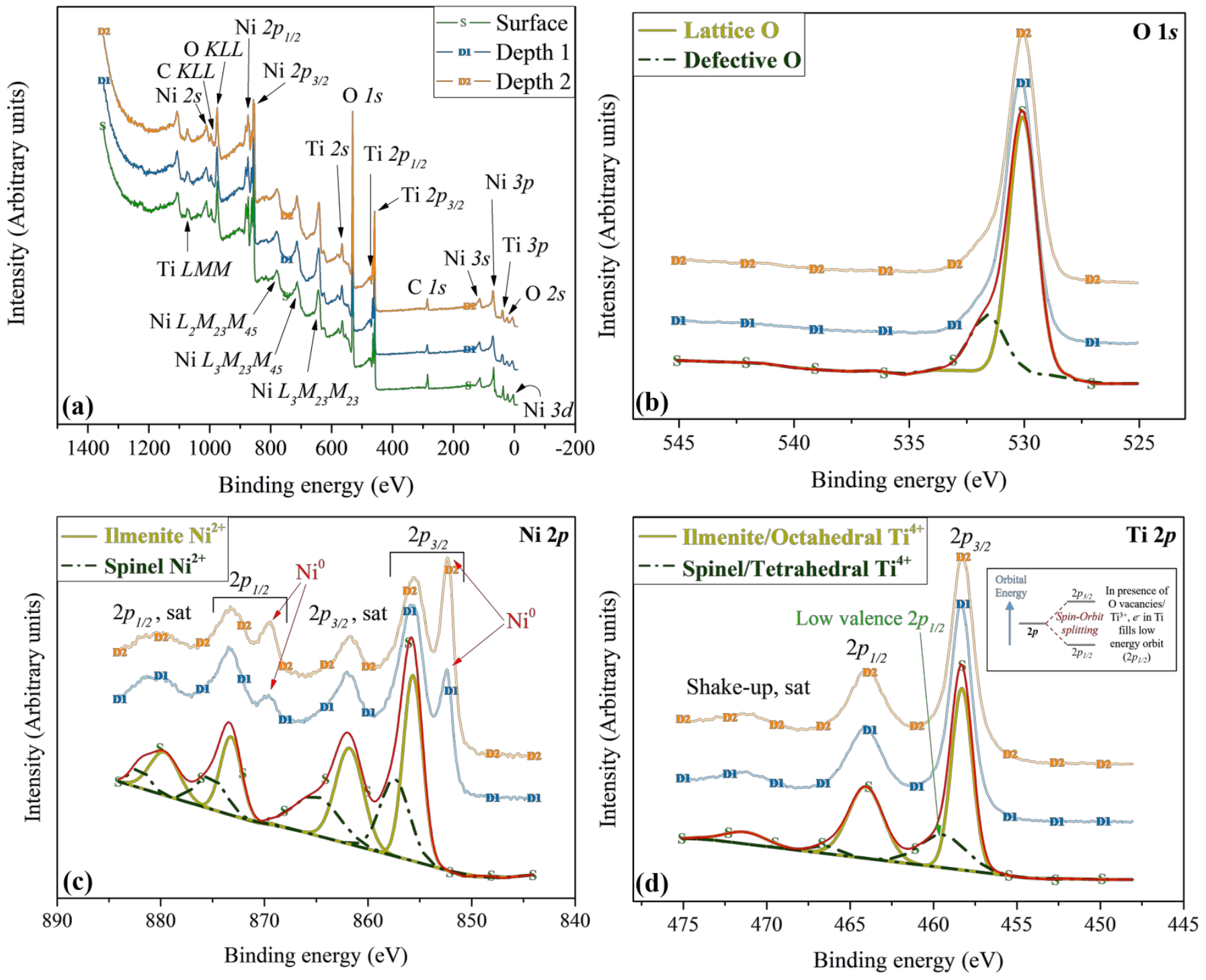

Figure 6 


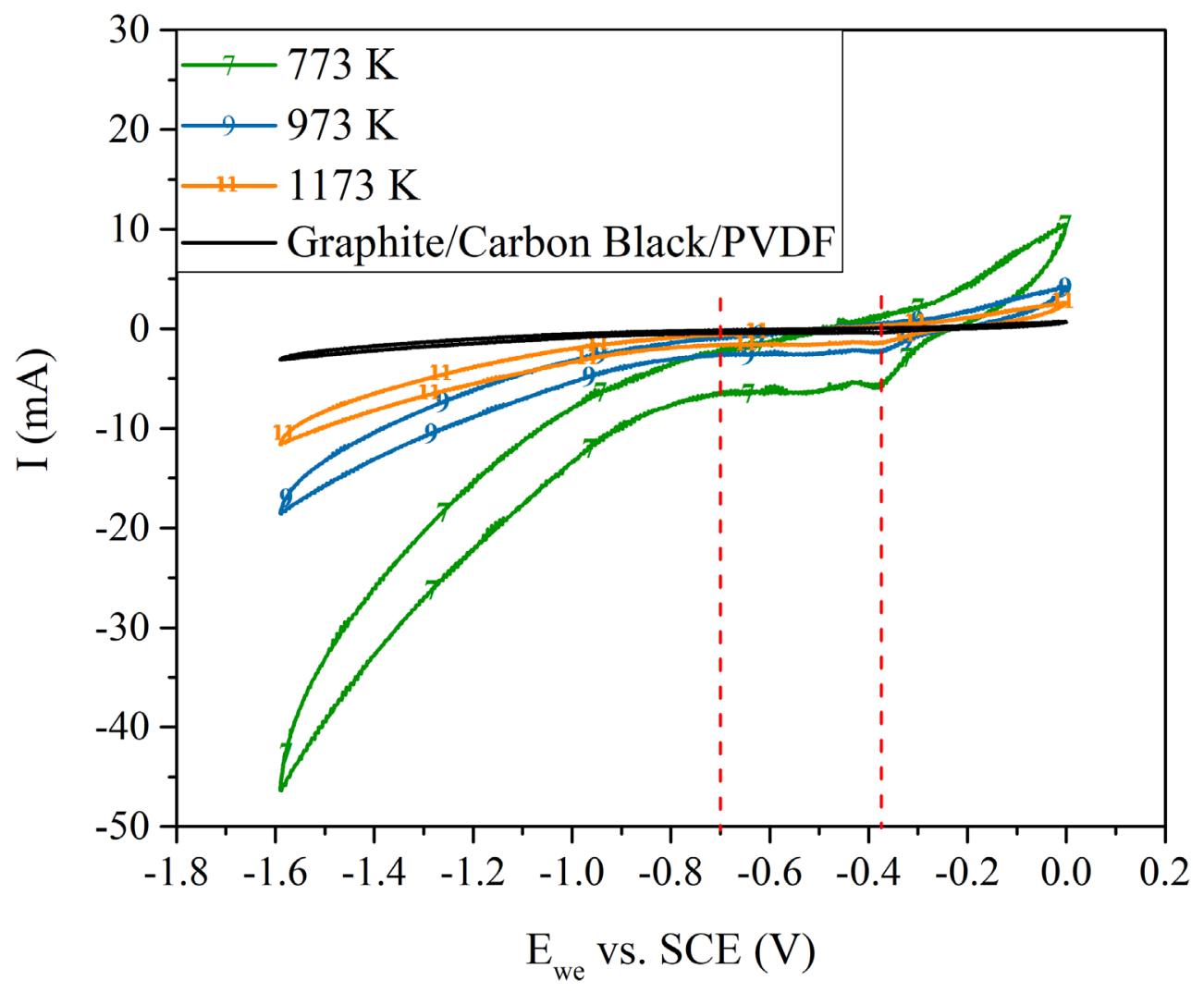

Figure 7 


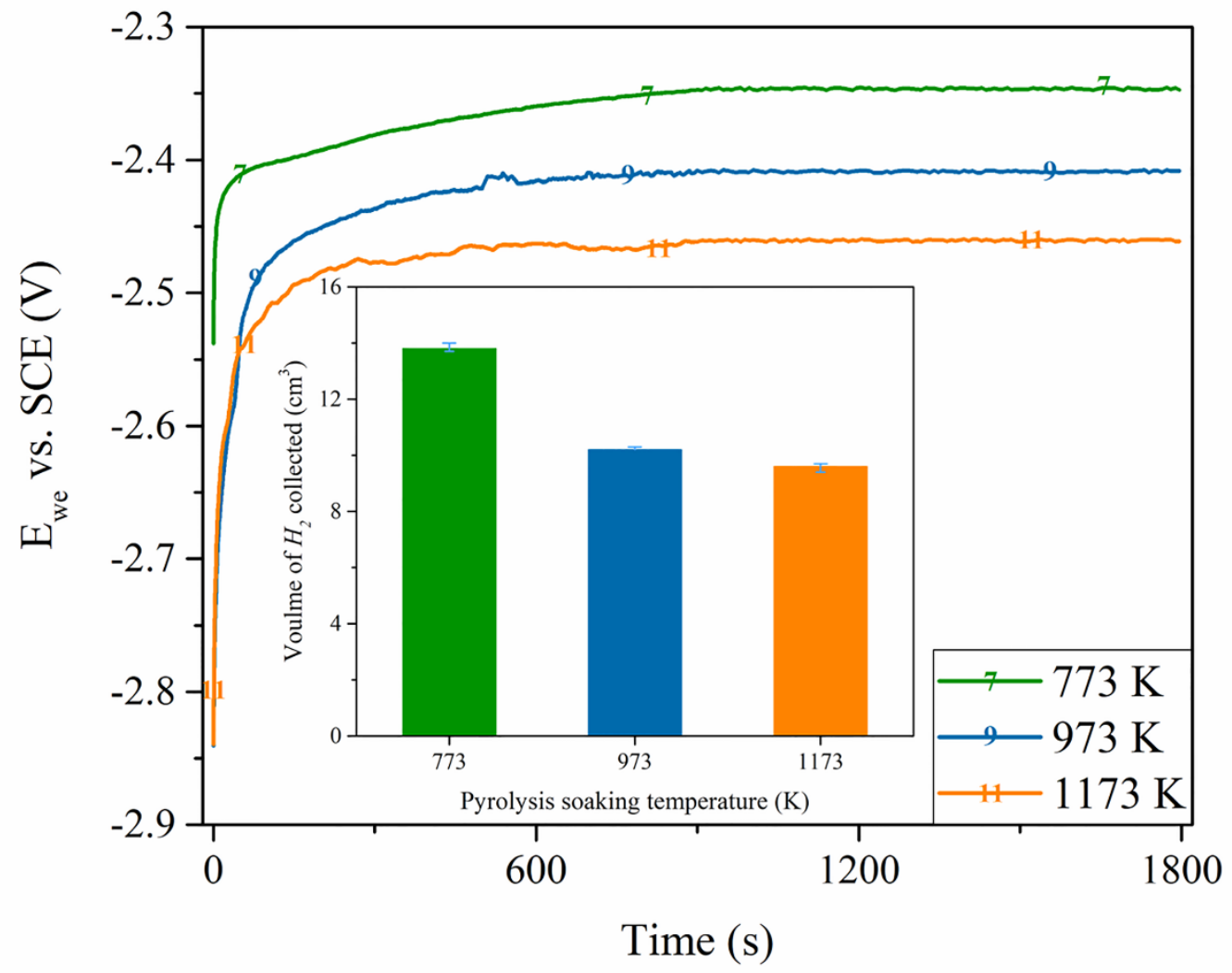

Figure 8 


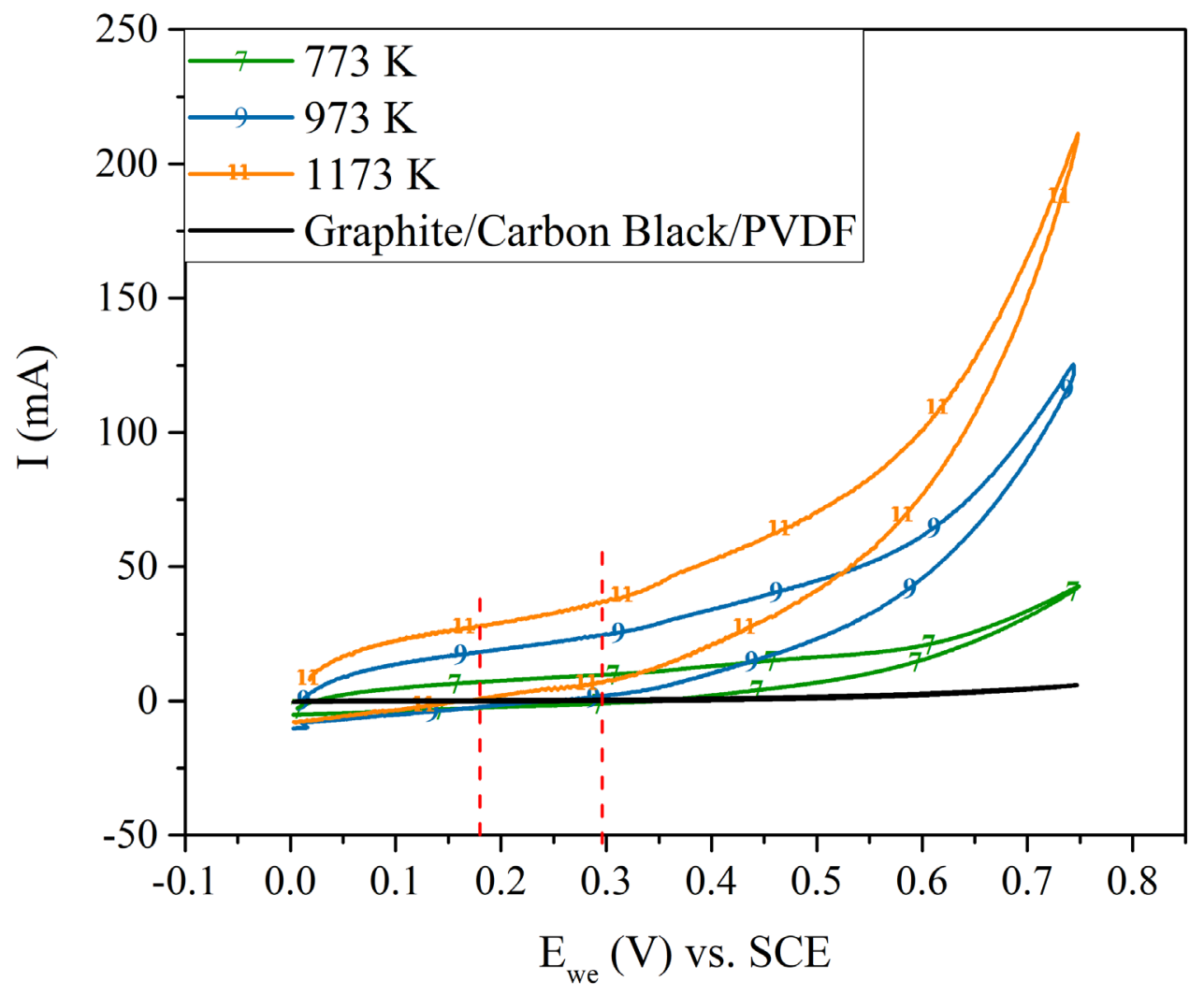

Figure 9 


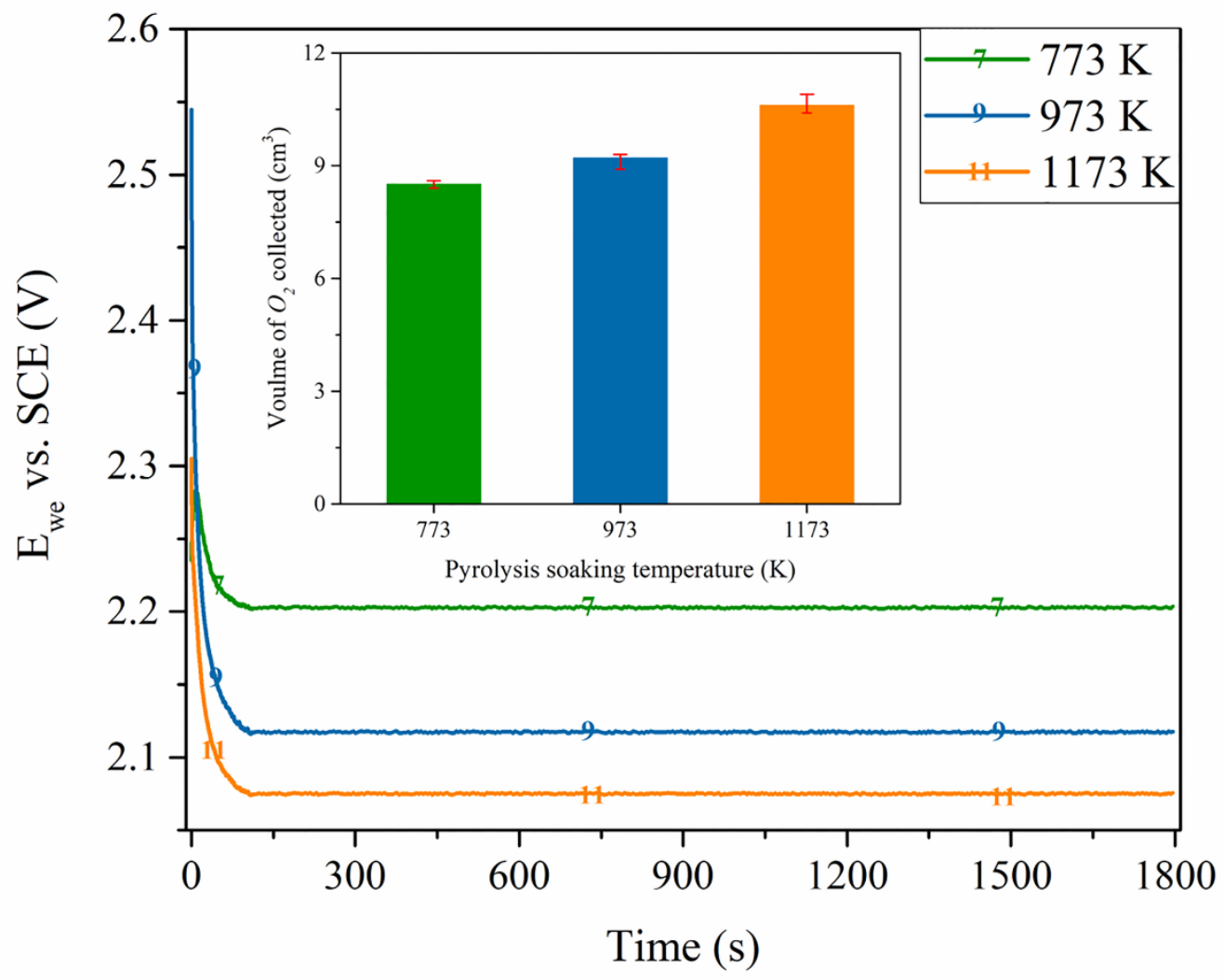

Figure 10 


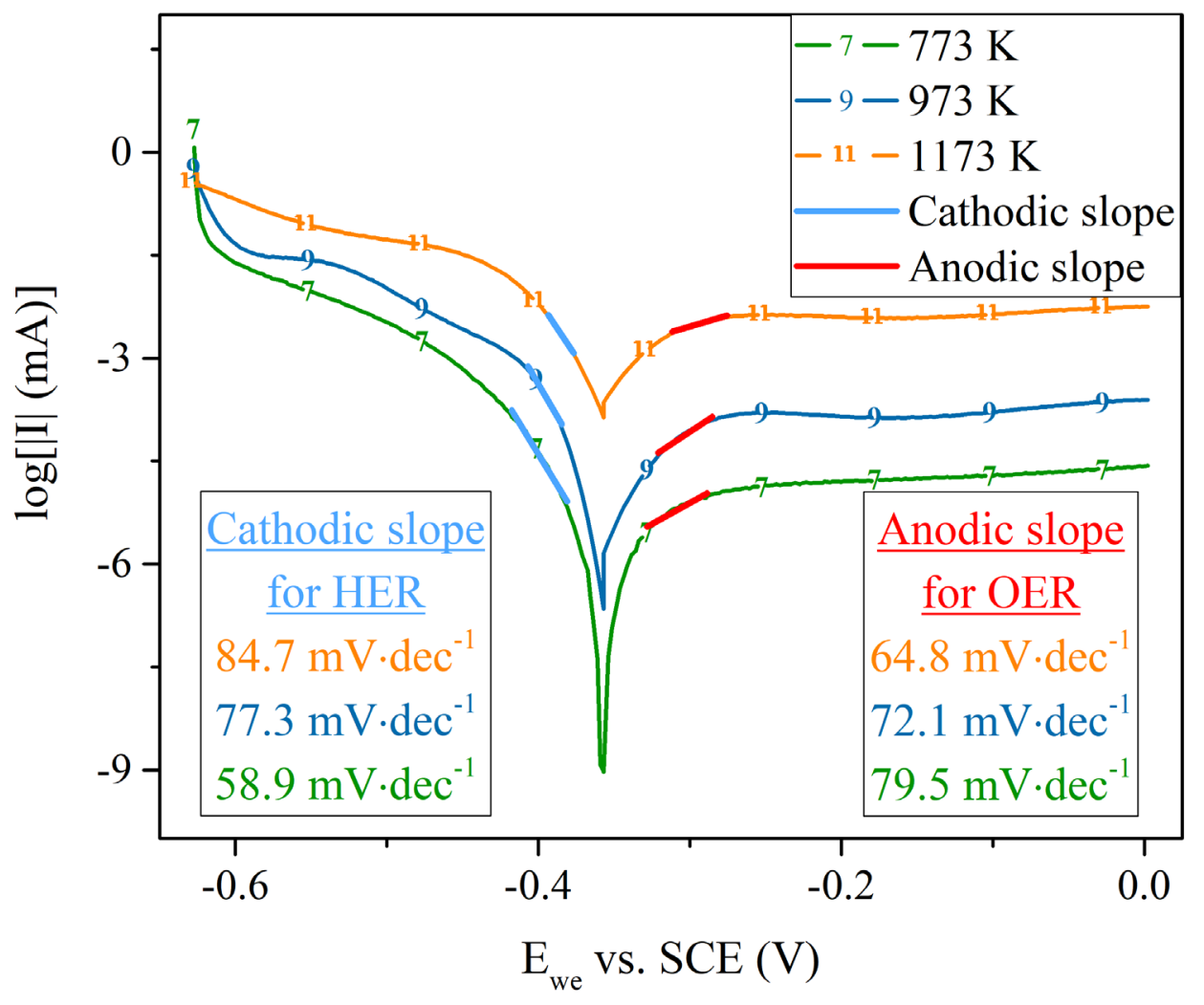

Figure 11 